Published in final edited form as:

J Am Chem Soc. 2006 February 1; 128(4): 1379-1389.

\title{
Models of the Membrane-Bound Cytochromes: Mössbauer Spectra of Crystalline Low-Spin Ferriheme Complexes Having Axial Ligand Plane Dihedral Angles Ranging from $0^{\circ}$ to $90^{\circ}$
}

\author{
Thomas Teschner $\ddagger$, Liliya Yatsunyk $\dagger$, Volker Schünemann ${ }^{\star}, \ddagger, \|$, Hauke Paulsen $\ddagger$, Heiner \\ Winkler $^{\ddagger}$, Chuanjiang Hu ${ }^{\sharp}$, W. Robert Scheidt ${ }^{\sharp}$, F. Ann Walker ${ }^{*}, \ddagger$, and Alfred X. Trautwein ${ }^{*}, \ddagger$ \\ $\ddagger$ Contribution from the Institut für Physik, Universität zu Lübeck, Ratzeburger Allee 160, D-23538 \\ Lübeck, Germany \\ †Contribution from the Department of Chemistry, The University of Arizona, Tucson, AZ \\ 85721-0041, USA \\ ||Contribution from the Technische Universität Kaiserslautern, Fachbereich Physik, Erwin- \\ Schrödinger-Str. 56, D-67663 Kaiserslautern \\ $\#$ Contribution from the Department of Chemistry and Biochemistry, University of Notre Dame, Notre \\ Dame, IN 46556-5670, USA
}

\begin{abstract}
Crystalline samples of four low-spin Fe(III) octaalkyltetraphenylporphyrinate and two low-spin Fe (III) tetramesitylporphyrinate complexes, all of which are models of the bis-histidine-coordinated cytochromes of mitochondrial complexes II, III and IV, and chloroplast complex $b_{6} f$, and whose molecular structures and EPR spectra have been reported previously, have been investigated in detail by Mössbauer spectroscopy. The six complexes and the dihedral angles between axial ligand planes of each are [(TMP) Fe(1-MeIm $\left.)_{2}\right] \mathrm{ClO}_{4}\left(0^{\circ}\right.$, paral-[(OMTPP $\left.) \mathrm{Fe}(1-\mathrm{MeIm})_{2}\right] \mathrm{Cl}\left(19.5^{\circ}\right.$, paral-[(TMP) $\mathrm{Fe}(5-\mathrm{MeHIm})_{2} \mathrm{ClO}_{4}\left(26^{\circ}, 30^{\circ}\right.$ for two molecules in the unit cell whose EPR spectra overlap), $\left[(\mathrm{OETPP}) \mathrm{Fe}\left(4-\mathrm{Me}_{2} \mathrm{NPy}\right)_{2}\right] \mathrm{Cl}\left(70^{\circ}\right.$, perp-[(OETPP $\left.) \mathrm{Fe}(1-\mathrm{MeIm})_{2}\right] \mathrm{Cl}\left(73^{\circ}\right.$, and perp-[(OMTPP $) \mathrm{Fe}(1-$ $\mathrm{MeIm})_{2} \mathrm{Cl}\left(90^{\circ}\right.$. Of these, the first three have been shown to exhibit normal rhombic EPR spectra with three clearly-resolved g-values, while the last three have been shown to exhibit "large g $\max$ " EPR spectra at $4.2 \mathrm{~K}$. It is found that the hyperfine coupling constants of the complexes are consistent with those reported previously for low-spin ferriheme systems, with the largest-magnitude hyperfine coupling constant, $\mathrm{A}_{\mathrm{zz}}$, being considerably smaller for the "parallel" complexes (400-540 kG) than for the strictly perpendicular complex $(902 \mathrm{kG}), \mathrm{A}_{\mathrm{xx}}$ being negative for all six complexes, and $\mathrm{A}_{\mathrm{zz}}$ and $A_{x x}$ being of similar magnitude for the "parallel" complexes (for example, for [(TMP)Fe(1$\left.\mathrm{MeIm})_{2}\right] \mathrm{Cl}, \mathrm{A}_{\mathrm{zz}}=400 \mathrm{kG}, \mathrm{A}_{\mathrm{xx}}=-400 \mathrm{kG}$ ), and finally, $\mathrm{A}_{\mathrm{yy}}$ is small, but difficult to estimate with accuracy for all complexes. With results for six structurally-characterized model systems we find qualitative correlations of $\mathrm{g}_{\mathrm{zz}}, \mathrm{A}_{\mathrm{zz}}$, and $\Delta \mathrm{E}_{\mathrm{Q}}$ with axial ligand plane dihedral angle $\Delta \varphi$.
\end{abstract}

\footnotetext{
*Contact Information: awalker@u.arizona.edu, Tel. ++1 520 621-8645, Fax ++1 520 626-9300;schuene@ physik.uni-kl.de, Tel. ++49 (0) 631 205-4920, Fax. ++49 (0) 631 205-4958;trautwein@ physik.uni-luebeck.de, Tel. ++49 (0) 451 500-4200, Fax ++49 (0) 451 500-4214.

Supporting Information Available: Additional Mössbauer spectra of complexes (Figures S1-S8), iron-iron distances in the six crystalline solids (Table S1), and ligand deviations from the normal to the mean porphyrin plane and ligand plane orientations with respect to the $\mathrm{N}-\mathrm{Fe}-\mathrm{N}$ axes for the complexes of this study (Table S2). This material is available free of charge via the Internet at http://pubs.acs.org
} 


\section{Introduction}

Heme-containing electron transfer proteins are essential to many biological processes. The two major classes of heme-based electron transport proteins, having bis-histidine- and histidinemethionine-coordinated heme centers, shuttle between iron(II) and iron(III) oxidation states and are usually called the cytochromes $a, b$, and $c$, based on the differing substituents on the periphery of the heme. In addition to relatively small molecular weight heme proteins, ${ }^{1-9}$ a number of cytochrome-containing multi-heme protein complexes with bis-histidine coordination are known. These include the cytochromes $b$ of mitochondrial complexes II, 10-13 III ${ }^{14-24}$ and chloroplasts, ${ }^{25-27}$ the cytochrome $a$ of mitochondrial complex IV (cytochrome oxidase), ${ }^{28}$ as well as bacterial analogs of these multi-heme electron-transfer proteins and a number of additional multiheme cytochromes $c$ that are involved in electron transfer and/or redox of the oxides of nitrogen, ${ }^{29-32}$ sulfur, 33 and other main group elements. Complex III, also called the cytochrome $b c_{l}$ complex or ubiquinol:cytochrome $c$ oxidoreductase, plays an important role in the electron transfer process in mitochondria, chloroplasts, and in many aerobic and photosynthetic bacteria. It transfers electrons from ubiquinol to soluble cytochrome $c$; this process is coupled to translocation of two protons across the inner mitochondrial membrane. ${ }^{34}$ Cytochrome $b_{6} f$ of photosynthetic bacteria and chloroplasts transfers electrons from the lipophilic plastoquinol (a 2-electron donor), which was prereduced by Photosystem II, to a hydrophilic 1-electron acceptor (a $c$-type cytochrome for photosynthetic bacteria or plastocyanin for chloroplasts) that then reduces Photo-system I, and couples this electron transfer to translocation of two protons across the chloroplast membrane. ${ }^{35}$ The characterization and mechanistic understanding of these large molecular weight, membrane-bound, multi-heme systems continues to be a significant challenge.

One of the first and most useful spectroscopic tools that provided much insight into the number, properties and roles of the heme centers in the cytochrome $b c_{1}$ complex was EPR spectroscopy. The unusual EPR spectra for the cytochrome $b c_{1}$ complex were first reported by Orme-Johnson, Hansen and Beinert ${ }^{36}$ and later analyzed in detail by Salerno. ${ }^{37}$ EPR data for the $b c_{1}$ complex show that both of the $b$ hemes (as well as the $c_{l}$ heme) exhibit the single feature EPR signals known as "HALS' (highly anisotropic low-spin) or preferably, "large g $\mathrm{gax}_{\text {max }}$ "38 type with $\mathrm{g}_{\max }=3.41-3.44$ and 3.75-3.78 for low and high reduction potential hemes, $b_{L}$ and $b_{H}$, respectively. Cytochrome $b_{6} f$ does not yield a resolved EPR signal for the hemes of cytochrome $b_{6}$ (except for the high-spin heme sometimes called heme $x^{27}$ ), but the g-values of hemes $b_{l}$ and $b_{h}$ (also called $b_{n}$ and $b_{p}$ ) have been estimated as 3.6 by magnetic Mössbauer spectroscopy. ${ }^{39}$ For the cytochrome $b c_{1}$ complex of mitochondria and the structurally- and functionallyrelated cyto-chrome $b_{6} f$ complex of chloroplasts, these "large g max" EPR signals "relax" to normal rhombic EPR signals (with $\mathrm{g}_{1}, \mathrm{~g}_{2}$ and $\mathrm{g}_{3}$ values observed, and typically $2.9,2.25,1.54$, respectively) when the cytochrome $b$ protein is extracted from the membrane and the other proteins of the complex. $40-42$

In earlier work with bis-imidazole-ligated iron(III) porphyrinates, we have found that the axial ligand arrangement, i.e., the absolute and relative orientations of the two planar axial ligands, is an important factor in defining the EPR spectroscopic properties. ${ }^{38,43-46}$ Ligand orientation is also likely to be a significant determinant of the reduction potentials of these heme centers. Studies with synthetic ferriheme complexes have shown that the coordination of bulky imidazoles (2-methylimidazole, 1,2-dimethylimidazole, etc.) or some pyridines (3,4dimethylaminopyridine, pyridine itself, etc.) to iron(III) tetraphenylporphyrin (TPPFe(III)) 38,43 or hemin itself ((ProtoIX)Fe(III)) ${ }^{47,48}$ leads to a "large g gax" EPR signal similar to that reported for the $b c_{1}$ complex. ${ }^{36,37}$ These signals have one g value 3.2 (sometimes as large as 3.78 ), nearly or completely undetectable $g_{2}$ and $g_{3}$, and is observable only at very low temperature ( $<10 \mathrm{~K}$ in most cases). ${ }^{47}$ It was first shown by Walker, Scheidt and their coworkers to occur for ferriheme complexes with a $\left(\mathrm{d}_{\mathrm{xy}}\right)^{2}\left(\mathrm{~d}_{\mathrm{xz}}, \mathrm{d}_{\mathrm{yz}}\right)^{3}$ electronic ground state in which the 
splitting between the $\mathrm{d}_{\mathrm{xz}}$ and $\mathrm{d}_{\mathrm{yz}}$ orbitals is small (usually less than the value of the spin-orbit coupling constant, $\lambda$, or $\left.<400 \mathrm{~cm}^{-1}\right) .38,45,49,50$ This is the case where axial ligands are in perpendicular planes 38,49 or where ligands without planes are used (e.g. $\mathrm{CN}^{-}, 44,51$ phosphines ${ }^{49}$ or $\mathrm{NH}_{3}{ }^{49}$ or alkyl amines, as in cyto-chrome $f^{52}$ ). On the other hand, normal rhombic EPR signals are observed when the splitting between the $\mathrm{d}_{\mathrm{xz}}$ and $\mathrm{d}_{\mathrm{yz}}$ orbitals is larger, on the order of 2-3 times the spin-orbit coupling constant, $\lambda, 600-1000 \mathrm{~cm}^{-1} .38,45,49$ In this case planar axial ligands coordinated to iron are oriented in parallel planes. Hence, the first correlation of structure with EPR spectral type was established: "large g max" spectra indicate axial ligands in perpendicular planes, while normal rhombic spectra indicate axial ligands in parallel planes. 46

The systems investigated as models of the bis-histidine-coordinated cytochromes have all utilized synthetic hemes such as octaethylporphyrinatoiron(III)/(II), (OEP)Fe, tetraphenylporphyrinatoiron(III)/(II), (TPP)Fe, or other tetraarylporphyrin-type systems such as tetramesitylporphyrinatoiron(III)/(II), (TMP)Fe, ${ }^{45,49,53-55}$ and more recently, octaalkyltetraphenylporphinatoiron(III), (OETPP)Fe, (OMTPP)Fe, and (TC 6 TPP)Fe, 46,56, 57 in each case with two imidazole or high-basicity pyridine axial ligands. Knowledge from these model heme systems has been applied to the interpretation of the heme proteins such as the cytochrome-containing systems of Complexes II and III of inner mitochondrial membranes. At the highest resolution obtained thus far $(2.1 \AA), 58$ the bovine cytochrome $b c_{1}$ complex structure has the two $b$ heme centers with axial histidine imidazole plane dihedral angles of $90^{\circ}$ and $61^{\circ}$; the yeast structure, with highest resolution $2.3 \AA, 17,18$ has those same angles as $97^{\circ}$ and $70^{\circ}$. The larger-dihedral angle heme center, $b_{L}$, has been assigned the EPR signal with $\mathrm{g}_{\max }=3.75-3.78$ and the smaller-dihedral angle one, $b_{H}$, has been assigned the EPR signal with $g_{\max }=3.41-3.44$ on the basis of EPR spectra obtained during redox titrations. $37,59,60$ Reduction potentials for the $b_{L}$ and $b_{H}$ centers of murine Complex III are $-31 \pm 12$ and $+92 \pm$ $14 \mathrm{mV}$, respectively, ${ }^{61}$ and those for other mammalian $b$ heme centers are similar, but all are affected by the conditions used, including detergent or lipid, as well as the presence of inhibitors that bind to the quinone sites, and the state of oxidation of the quinone near heme $b_{H} 62$.

Mössbauer spectroscopy is another technique that has been utilized to characterize some ferriheme protein systems, ${ }^{39,63-69}$ but no investigations of the mitochondrial complexes II, III and IV have yet been reported. The magnetic Mössbauer spectra of several multi-heme protein complexes have been reported, $67,69,39$ although it is very difficult to deconvolute the overlapping Mössbauer spectra of multi-heme complexes when the parameters are fairly similar. Therefore, investigations of synthetic ferriheme models by Mössbauer spectroscopy can be helpful in interpreting the complex patterns observed for multi-heme complexes. The magnetic Mössbauer spectra of some OEP, TPP, TMP and other phenyl-substituted TPP complexes of $\mathrm{Fe}(\mathrm{III})^{38,54,70-72}$ and $\mathrm{Fe}$ (II) ${ }^{73-75}$ have been reported previously. These studies have clearly shown that the Möss-bauer quadrupole splittings in zero applied magnetic field are sensitive to the axial ligand orientation, $38,54,70-72$ and at least the broad categories of parallel and perpendicular relative ligand orientation can be distinguished. Furthermore, by fitting the magnetic Mössbauer spectra, the two unobserved g-values in the EPR spectra of "large $g_{\max }$ " centers can be estimated. 38,54,70-72 How-ever, while the largest hyperfine coupling constant, $\mathrm{A}_{\mathrm{zz}}$, can be estimated very accurately from the spread of the magnetic Mössbauer spectrum, the two smaller-magnitude hyperfine coupling constants, $\mathrm{A}_{\mathrm{yy}}$ and $\mathrm{A}_{\mathrm{xx}}$, are usually less accurately determined by the spectral fits, ${ }^{72}$ and thus the values of the other two g-values, $g_{y}$ and $g_{x}$, usually cannot be as well defined as desired. Furthermore, from magnetic Mössbauer and EPR spectra alone, it is sometimes not possible to determine unambiguously whether $g_{z}$ or $g_{x}$ is the largest $g$-value, and thus it cannot be stated with certainty whether the unpaired electron is in the $\mathrm{d}_{\mathrm{yz}}$ or the $\mathrm{d}_{\mathrm{xy}}$ orbital, respectively. ${ }^{72}$ In these cases (where the rhombicity, V/ $\triangle$, is greater than 2/3), single crystal EPR data or pulsed EPR data on frozen solution samples are required to determine the orientation of the g-tensor and thus 
whether the electron configuration is $\left(\mathrm{d}_{\mathrm{xy}}\right)^{2}\left(\mathrm{~d}_{\mathrm{xz}}, \mathrm{d}_{\mathrm{yz}}\right)^{3}$ or $\left(\mathrm{d}_{\mathrm{xz}}, \mathrm{d}_{\mathrm{yz}}\right)^{4}\left(\mathrm{~d}_{\mathrm{xy}}\right)^{1} .71,76,77$ However, this is not a problem for bis-histidine-coordinated cytochromes and their models, which have all long been known to have $\left(\mathrm{d}_{\mathrm{xy}}\right)^{2}\left(\mathrm{~d}_{\mathrm{xz}}, \mathrm{d}_{\mathrm{yz}}\right)^{3}$ electron configurations, ${ }^{78-81}$ and thus for these systems the Möss-bauer spectra can be unambiguously interpreted in terms of the latter electron configuration.

In this study, we have investigated whether there may be a more quantitative relationship between the axial ligand plane dihedral angle and the Mössbauer parameters observed for model heme complexes, and whether crystalline samples might lead to more precise fitting of the magnetic Mössbauer spectra. Accordingly, in this paper we describe the Mössbauer spectra of six crystalline complexes, [(OETPP)Fe $\left.\left(4-\mathrm{Me}_{2} \mathrm{NPy}\right)_{2}\right]^{+}$, perp-[(OETPP $\left.) \mathrm{Fe}(1-\mathrm{MeIm})_{2}\right]^{+}$, $\left[(\mathrm{TMP}) \mathrm{Fe}(1-\mathrm{MeIm})_{2}\right]^{+}$, paral-[(TMP)Fe(5-MeHIm $\left.)_{2}\right]^{+}$, and two of [(OMTPP)Fe(1$\left.\mathrm{MeIm})_{2}\right]^{+}$with different axial ligand plane dihedral angles, $\Delta \varphi$. Structural data are available for all of these complexes, ${ }^{54-57}$ and the crystalline samples used for the Mössbauer spectral investigations utilized the exact same crystalline form as that used for the structure determinations. The axial ligand plane dihedral angles span the entire possible range of $0^{\circ}$ to $90^{\circ}$. Three complexes display normal rhombic EPR spectra (dihedral angles $0^{\circ}, 5419.5^{\circ} 57$ and $26^{\circ}, 30^{\circ 55,82}$ ); the remainder exhibit "large $g_{\max }$ " EPR signals at $4.2 \mathrm{~K} .{ }^{56,57}$ These latter three complexes were the ones we were most interested in studying. As it turns out, all six of the complexes provided new information that is valuable to our understanding of the magnetic spectroscopic properties of these types of ferriheme systems, and the results show us clearly that the difficulties encountered previously in fitting the Möss-bauer spectra of ferriheme model complexes in frozen solution or solid samples precipitated rapidly from solution ${ }^{72}$ probably arose from the presence of multiple orientations of the axial ligands within the two broad classes of ligand orientations.

\section{Experimental}

The crystalline samples of paral-[(TMP)Fe(5-MeHIm $\left.)_{2}\right] \mathrm{ClO}_{4},\left[(\mathrm{TMP}) \mathrm{Fe}(1-\mathrm{MeIm})_{2}\right] \mathrm{ClO}_{4}$, paral-[(OMTPP)Fe(1-MeIm $\left.)_{2}\right] \mathrm{Cl}$, perp-[(OMTPP $\left.) \mathrm{Fe}(1-\mathrm{MeIm})_{2}\right] \mathrm{Cl}$, perp-[(OETPP)Fe(1$\left.\mathrm{MeIm})_{2}\right] \mathrm{Cl}$ and [(OETPP)Fe(4-Me $\left.\left.2 \mathrm{NPy}\right)_{2}\right] \mathrm{Cl}$, whose crystal and molecular structures are known, were prepared as described previously. ${ }^{54-57}$ Polycrystalline natural iron-containing samples for Mössbauer spectroscopy were placed in solid Delrin ${ }^{\odot}$ sample holders and covered with a minimum of mother liquor for the octaalkyltetraphenylporphyrinates, which contain solvent molecules of crystallization, 56,57 or without mother liquor for the TMP complexes, which do not. ${ }^{54,55}$ They were cooled to $233 \mathrm{~K}$ during shipping and then stored at $77 \mathrm{~K}$.

Mössbauer spectra were recorded using a conventional spectrometer in the constantacceleration mode. Isomer shifts are given relative to $\alpha$-Fe at room temperature. The spectra obtained at $20 \mathrm{mT}$ were measured in a liquid helium bath cryostat (Oxford MD 306) equipped with a pair of permanent magnets. For the high-field spectra a cryostat equipped with a superconducting magnet was used (Oxford Instruments). Magnetically split spectra of paramagnetic samples were simulated in the spin-Hamiltonian approximation described below, otherwise spectra were analyzed by least-square fits using Lorentzian line shapes.

The Zeeman interaction of a spin with an applied field $\vec{B}$ and $\stackrel{\leftrightarrow}{g}$ describing the electronic $g$ tensor is given by the Hamiltonian

$$
\hat{H}_{e l}=\mu_{B} \vec{S} g \vec{B}
$$

where $\mu_{B}$ denotes the Bohr magneton. Magnetic Mössbauer spectra were simulated using Eq. (1) together with the nuclear Hamiltonian 83 
$\hat{H}_{N}=\frac{e Q V_{z z}}{4 I(2 I-1)}\left[3 \hat{I}_{z}^{2}-I(I+1)+\eta\left(\hat{I}_{x}^{2}-\hat{I}_{y}^{2}\right)\right]-g_{N} \mu N \vec{I} \vec{B}+\langle\vec{S}\rangle \stackrel{\leftrightarrow}{A} \vec{I}$

$\mu_{B}$ Here $I$ denotes the nuclear spin quantum number, $Q$ the nuclear quadrupole moment of the excited nuclear state, $V_{z z}$ the z-component of the electric-field gradient (EFG) tensor and $\eta=$ $\left(V_{x x} V_{y y}\right) / V_{z z}$ the asymmetry parameter of the EFG, $g_{N}$ the nuclear g-factor, $\langle\vec{S}\rangle$ the electron spin expectation value, and $\mu_{N}$ the nuclear magneton. Note that the axis system being used for the EFG is that of the g- and A-tensors, i.e., with $z$ along the normal to the porphyrin plane and $x, y$ axes in the porphyrin plane. ${ }^{45,46,80}$ The g-tensor normalization condition $\mathrm{g}_{\mathrm{xx}} 2+\mathrm{g}_{\mathrm{yy}}{ }^{2}+$ $\mathrm{g}_{\mathrm{zz}} 2=16^{80,84,85}$ was used in this fitting procedure.

\section{Results and Discussion}

X-band EPR spectra of all samples of this study have already been reported, ${ }^{54-57}$ and are summarized in Table 1, where $x, y$ and $z$ axes are defined in terms of the molecular frame, with $z$ oriented along the heme normal and $x, y$ in the porphyrin plane. Field dependant Mössbauer spectra, obtained at $4.2 \mathrm{~K}$, of perp-[(OMTPP $\left.) \mathrm{Fe}(1-\mathrm{MeIm})_{2}\right] \mathrm{Cl}\left(\Delta \varphi=90^{\circ}\right.$ are shown in Figure 1. The spectrum of perp-[(OMTPP) $\left.\mathrm{Fe}(1-\mathrm{MeIm})_{2}\right] \mathrm{Cl}$, recorded in the presence of a small magnetic field of $20 \mathrm{mT}$ perpendicular to the $\gamma$-beam (Figure 1a) (as well as the 4.0 and $7.0 \mathrm{~T}$ spectra (Figure $1 \mathrm{~b}$ and $\mathrm{c}$ )) exhibits a magnetically-split six-line pattern. Spectra acquired with the magnetic field applied parallel to the $\gamma$-beam are shown in Supporting Information Figure $\mathrm{S} 1$. Based upon the assumption that " $\mathrm{g}_{\max }$ " $=g_{z z}=3.61$, the spectra can be simulated with the following hyperfine coupling tensor elements: $A_{z z}=+902 \mathrm{kG}, A_{x x}=-225 \mathrm{kG}$, and $A_{y y}=293$ $\mathrm{kG}$ (Table 1). Applying the normalization condition for the g-tensor $\left(\sum g^{2}=16\right)$ leads to the best estimates of $g_{y y}$ and $g_{x x}$ of 1.53 and 0.63 , respectively. These values are thus used to calculate the crystal field parameters, Tetragonality and Rhombicity, ${ }^{80}$ given in Table 1.

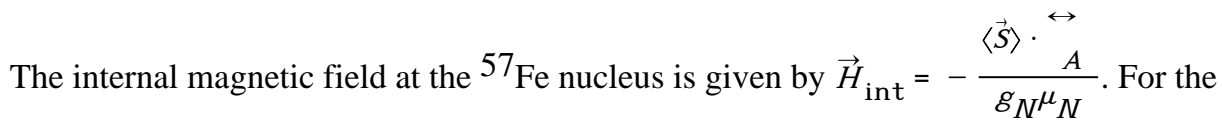
magnetic splitting the effective hyperfine field, which is the sum of the external and the internal field, must be considered. Nevertheless, the internal field dominates strongly, and therefore the magnetic splitting of a ferric low-spin system is effectively determined by the product $\langle\vec{S}\rangle \cdot \leftrightarrow_{A}$. For $\mathrm{S}=1 / 2$ ferric ion the symmetry of the $\mathbf{g}$-tensor is reflected within directiondependent spin expectation values. The corresponding g-tensor component determines the sign of the corresponding spin expectation value. If the main axis system of the g- and A-tensors coincide, then the components of the internal hyperfine field at the ${ }^{57} \mathrm{Fe}$ nucleus are proportional to $\left\langle S_{i}\right\rangle$ with $i=x, y, z$ or, if the reference frames of the $\mathrm{g}$ - and A-tensors are collinear,to $\mathrm{g}_{\mathrm{ii}}$. $\mathrm{A}_{\mathrm{ii}}$. Clearly, for perp-[(OMTPP)Fe(1-MeIm) $\left.)_{2}\right] \mathrm{Cl}$ both $A_{z z}$ and $g_{z z}$ are the tensor components with the largest magnitude (Table 1). Therefore the magnetic splitting observed in the Mössbauer spectrum is determined mainly by the product $\left\langle S_{z}\right\rangle \cdot A_{z z}$ Moreeover, for all Type I complexes examined thus far the magnetic splitting is proportional to $g_{i j}$. $A_{i i}$ because at least the z-axes of the reference frames of the g- and the A-tensors coincide. ${ }^{72}$ Both $A_{x x}$ and $A_{y y}$ are significantly smaller than $A_{z z}$. As shown previously ${ }^{72}\left|A_{z z}\right|>>\left|A_{y y}\right|,\left|A_{x x}\right|$ holds for the Mössbauer spectra of all Type $\mathrm{I}^{45}$ complexes. Thus, for perp-[(OMTPP)Fe(1-MeIm) $\left.)_{2}\right] \mathrm{Cl}$ of this study (Figure 1, Supporting Information Figure S1, and Table 1), $A_{z z}$ is quite large and positive, $A_{y y}$ is approximately one-third of $\mathrm{A}_{\mathrm{zz}}$, and $\mathrm{A}_{\mathrm{xx}}$ has approximately the same magnitude as $A_{y y}$ and is negative.

In contrast to perp-[(OMTPP)Fe(1-MeIm $\left.)_{2}\right] \mathrm{Cl}$, the low field spectra $(20 \mathrm{mT}$ at $4.2 \mathrm{~K})$ of perp-[(OETPP)Fe(1-MeIm $\left.)_{2}\right] \mathrm{Cl}\left(\Delta \varphi=73.1^{\circ}\right.$ shown in Figure $2 \mathrm{a}$, and [(OETPP)Fe(4- 
$\left.\left.\mathrm{Me}_{2} \mathrm{NPy}\right)_{2}\right] \mathrm{Cl}\left(\triangle \varphi=70^{\circ}\right.$, shown in Supporting Information Figure S3a, exhibit broad asymmetric doublets, which indicates that the electron spin fluctuates with a rate, $\omega$, comparable to the Larmor frequency of the iron nucleus $\langle\vec{S}\rangle \cdot{ }_{A} / \hbar$ which is of the order of $10^{7} \mathrm{~s}^{-1}$. The quadrupole splitting, $\triangle \mathrm{E}_{\mathrm{Q}}$, is $1.94 \mathrm{~mm} / \mathrm{s}$ for perp-[(OETPP)Fe(1-MeIm $\left.)_{2}\right] \mathrm{Cl}$ $\left(\Delta \varphi=73.1^{\circ}\right.$ and $2.13 \mathrm{~mm} / \mathrm{s}$ for $\left[(\mathrm{OETPP}) \mathrm{Fe}\left(4-\mathrm{Me}_{2} \mathrm{NPy}\right)_{2}\right] \mathrm{Cl}\left(\Delta \varphi=70^{\circ}\right.$. The application of high magnetic fields slows down the electronic relaxation rate and magnetically split patterns are observed (Figure 2b and $\mathrm{c}$ and Supporting Information Figure S3). This means that in high magnetic fields the electron spin fluctuates with a rate slower than the Larmor frequency of the iron nucleus. The magnetic splittings observed for perp-[(OETPP)Fe(1-MeIm $\left.)_{2}\right] \mathrm{Cl}$ and $\left[(\mathrm{OETPP}) \mathrm{Fe}\left(4-\mathrm{Me}_{2} \mathrm{NPy}\right)_{2}\right] \mathrm{Cl}$ are (as in the case of the $90^{\circ}$ complex, perp-[(OMTPP)Fe(1$\left.\mathrm{MeIm})_{2}\right] \mathrm{Cl}$ ), dominated by $A_{z z}$. The values of $A_{z z}=712$ and $714 \mathrm{kG}$ obtained for these complexes are about $33 \%$ smaller than $A_{z z}$ of the $90^{\circ}$ complex, perp-[(OMTPP)Fe(1-MeIm) $)_{2}$ ] $\mathrm{Cl}$. The large values of $A_{z z}, g_{z z}$ and the negative values of $A_{x x}$ are typical of Type $\mathrm{I}^{45}$ complexes. The asymmetry parameter $\eta \approx-1$ means that the EFG tensor elements for the Type $\mathrm{I}^{45}$ complexes exhibit a small $V_{y y}$ while $V_{x x}$ and $V_{z z}$ are of similar magnitude but with a negative value of $V_{x x}$ (Table 1).

Figure 3 shows the Mössbauer spectra of paral-[(TMP)Fe(5-MeHIm $\left.)_{2}\right] \mathrm{ClO}_{4}\left(\Delta \varphi=26^{\circ}, 30^{\circ}\right.$ 82 . The spectrum obtained at $20 \mathrm{mT}$ (Figure $3 \mathrm{a}$ ) shows an asymmetric doublet, which indicates that the spin relaxation rate is faster than that of perp-[(OETPP)Fe(1-MeIm $\left.)_{2}\right] \mathrm{Cl}$. The application of large external fields perpendicular, Figure $3 \mathrm{~b}, \mathrm{c}$ and parallel (Supporting Figure S4) to the $\gamma$-beam slows down the relaxation and the spectral shape could be well reproduced with the parameters given in Table 1 . The quadrupole splitting of this complex is $2.59 \mathrm{~mm} / \mathrm{s}$, an increase of approximately $33 \%$ as compared to perp-[(OETPP)Fe(1-MeIm $\left.)_{2}\right] \mathrm{Cl}$ with $\Delta E_{Q}=1.94 \mathrm{~mm} / \mathrm{s}$. The higher value of the quadrupole splitting and the pattern of the magnetic Mössbauer spectra induced by the application of large external fields (Figures 3b,c and S4) are characteristic of most Type $\mathrm{II}^{45}$ centers. ${ }^{72}$ Likewise, [(TMP)Fe(1-MeIm) $)_{2} \mathrm{ClO}_{4}\left(\Delta \varphi=0^{\circ}\right.$ also shows an asymmetric doublet at $4.2 \mathrm{~K}$ in the presence of a $20 \mathrm{mT}$ field (Figure $4 \mathrm{a}$ ) with $\Delta E_{Q}=2.24 \mathrm{~mm} / \mathrm{s}$. The application of large external fields produced the spectra shown in Figure $4 b, c$ and Supporting Information Figure S6, where the spectral shapes were well reproduced with the parameters given in Table 1 The magnetic splitting of the Mössbauer signal of the solid-state, natural- abundance samples of paral-[(TMP)Fe(5-MeHIm $\left.)_{2}\right] \mathrm{ClO}_{4}$ and [(TMP)Fe(1-MeIm) $)_{2} \mathrm{ClO}_{4}$ is significantly smaller (as for other Type II centers ${ }^{72}$ ) than that of Type I centers (Figure 1 and reference ${ }^{72}$ ). Nevertheless, it is still dominated by $S_{z} . A_{z z}$, and the value of $A_{z z}(+489 \mathrm{kG})$ is the same in sign but smaller in magnitude than that of Type I complexes. In this case, the value of $A_{x x}$ is only somewhat smaller in magnitude than that of $A_{z z}$, but of opposite sign, and $A_{y y}$ is much smaller and positive, as observed previously. ${ }^{72}$

The magnetic field dependence of the Mössbauer spectra of paral-[(OMTPP)Fe(1-MeIm) $\left.)_{2}\right] \mathrm{Cl}$ $\left(\Delta \varphi=19.5^{\circ}\right.$ (Figure 5 and Supporting Information Figure S5) is comparable overall to those of paral-[(TMP)Fe(5-MeHIm $\left.)_{2}\right] \mathrm{ClO}_{4}\left(\Delta \varphi=26^{\circ}, 30^{\circ} 82\right.$ and [(TMP)Fe $\left.(1-\mathrm{MeIm})_{2}\right] \mathrm{ClO}_{4}(\Delta \varphi$ $=0^{\circ}$ (Figure 4 and Supporting Information Figure S6) discussed above. In a low field of 20 mT no significant magnetic splitting is observed; in fact, the spectrum of paral-[(OMTPP)Fe $\left.(1-\mathrm{MeIm})_{2}\right] \mathrm{Cl}$ shows a symmetrical doublet. The application of large external fields induces the magnetic splitting characteristic of Type II complexes. ${ }^{45,72}$ As mentioned in the caption to figure 5, these spectra were analyzed in the fast-relaxation limit, and yielded a value of $\mathrm{A}_{\mathrm{zz}}=499 \pm 15 \mathrm{kG}$. Analyzing the $7 \mathrm{~T}$ spectra in the slow-relaxation limit yielded $\mathrm{A}_{\mathrm{zz}}=450$ $\mathrm{kG}$, but within that limit it was not possible to find a unique set of parameters that also fits the spectra obtained at $4 \mathrm{~T}$. Therefore, we report only the data obtained from fits in the fastrelaxation limit. 
The question arises as to the reason for the different relaxation behavior of the complexes in this study. Ferriheme centers in proteins, such as the low-spin form of cytochrome $\mathrm{P} 450_{\text {cam }}$, 63 several electron-transfer cytochromes, ${ }^{64,65}$ the cytochrome $b_{6} f$ complex, ${ }^{39}$ and the histamine complexes of nitrophorins 2 and $4,86,87$ as well as ${ }^{57} \mathrm{Fe}$-labeled ferriheme models in frozen solution,including [(TPP)Fe $\left.\left(\mathrm{NH}_{2} \mathrm{PzH}\right)_{2}\right] \mathrm{Cl},{ }^{70}$ and perp-[(OMTPP $\left.) \mathrm{Fe}(1-\mathrm{MeIm})_{2}\right] \mathrm{Cl}$ of this study exhibit magnetically split Mössbauer spectra at $4.2 \mathrm{~K}$ in small applied fields. This indicates that the intrinsic relaxation rate, $\omega$, of the electron spin of most of these centers is slower than the Larmor frequency, about $10^{7} \mathrm{~s}^{-1}$. If the molecules are embedded in a crystal lattice, as in this study, spin-spin relaxation between nearby Fe(III) centers occurs, which speeds up the relaxation rate of the electron spin. This has also been observed for solid samples of the Type III center [(pTTP)Fe(2,6-XylylNC $\left.)_{2}\right] \mathrm{CF}_{3} \mathrm{SO}_{3}, 88$ the $4.2 \mathrm{~K}$ Mössbauer spectra of which have been analyzed in the intermediate spin-spin-relaxation regime by the dynamic lineshape formalism of Blume and Clauser. ${ }^{89}$

The slow-relaxing $90^{\circ}$ complex, perp-[(OMTPP $\left.) \mathrm{Fe}(1-\mathrm{MeIm})_{2}\right] \mathrm{Cl}$, with Type I EPR and Mössbauer spectra, has a unit cell with $I-43 d$ symmetry, in which every molecule has 8 nearest iron neighbors at a distance of $12.232 \AA$, four at $14.620 \AA$ and eight at $17.906 \AA$. The fastrelaxing $19.5^{\circ}$ complex paral-[(OMTPP)Fe(1-MeIm $\left.)_{2}\right] \mathrm{Cl}$, with Type II EPR and magnetic Mössbauer spectra, has a unit cell with $P c$ symmetry, in which every molecule has two nearest iron-iron distances of $9.54 \AA$, two of $10.128 \AA$ and two of $12.15 \AA$. Thus the much closer ironiron distances in paral-[(OMTPP $\left.) \mathrm{Fe}(1-\mathrm{MeIm})_{2}\right] \mathrm{Cl}$ as compared to perp-[(OMTPP $) \mathrm{Fe}(1-$ $\left.\mathrm{MeIm})_{2}\right] \mathrm{Cl}$ lead to an increase in the spin-spin relaxation rate, which manifests itself in the observation of a symmetrical doublet in the Mössbauer spectrum at $4.2 \mathrm{~K}$ and $20 \mathrm{mT}$ (Figure 5a). The $73.1^{\circ}$ sample, perp-[(OETPP)Fe(1-MeIm $\left.)_{2}\right] \mathrm{Cl}$, which exhibits Type $\mathrm{I}^{45} \mathrm{EPR}$ and magnetic Mössbauer spectra (Figure 2b,c), has a unit cell with two nearest iron-iron distances of $12.651 \AA$ and two of $12.86 \AA$, suggesting that this sample might also exhibit in its Mössbauer spectrum at $4.2 \mathrm{~K}$ and $20 \mathrm{mT}$ a relaxation pattern different from the sharp doublet observed for paral-[(OMTPP $\left.) \mathrm{Fe}(1-\mathrm{MeIm})_{2}\right] \mathrm{Cl}$. This is indeed the case; the complex shows intermediate relaxation (Figure 2a), much slower than observed for paral-[(OMTPP)Fe(1-MeIm $\left.)_{2}\right] \mathrm{Cl}$ (Figure 5a), but faster than that for perp-[(OMTPP)Fe(1-MeIm $\left.)_{2}\right] \mathrm{Cl}$ (Figure 1a). The same is true for the $70^{\circ}$ sample, $\left[(\mathrm{OETPP}) \mathrm{Fe}\left(4-\mathrm{Me}_{2} \mathrm{NPy}\right)_{2}\right] \mathrm{Cl}$, Supporting Information Figure S3a, which has two iron-iron distances of $12.245 \AA$, two of $13.651 \AA$, and four of $14.052 \AA$. The remaining two complexes, [(TMP)Fe(5-MeHIm $\left.)_{2}\right] \mathrm{ClO}_{4}\left(\Delta \varphi=26^{\circ}, 30^{\circ} 82\right.$ and [(TMP)Fe(1$\mathrm{MeIm})_{2} \mathrm{ClO}_{4}\left(\Delta \varphi=0^{\circ}\right.$, both exhibit asymmetric doublets at $4.2 \mathrm{~K}$ and $20 \mathrm{mT}$ (Figures $3 \mathrm{a}$ and $4 \mathrm{a}$, respectively), but these doublets are much sharper than those for [(OETPP)Fe(4-

$\left.\left.\mathrm{Me}_{2} \mathrm{NPy}\right)_{2}\right] \mathrm{Cl}\left(\Delta \varphi=70^{\circ}\right.$, Figure S3a) and perp-[(OETPP $\left.) \mathrm{Fe}(1-\mathrm{MeIm})_{2}\right] \mathrm{Cl}\left(\Delta \varphi=73.1^{\circ}\right.$, Figure 2a). Correspondingly, the nearest iron-iron distances (two nearest iron neighbors at $10.670 \AA$ and two at $10.409 \AA$, respectively) are intermediate between those of paral$\left[(\mathrm{OMTPP}) \mathrm{Fe}(1-\mathrm{MeIm})_{2}\right] \mathrm{Cl}$ and perp-[(OMTPP $\left.) \mathrm{Fe}(1-\mathrm{MeIm})_{2}\right] \mathrm{Cl}$, as is their relaxation behavior. The correlation between the number of iron neighbors, iron-iron distances and the relaxation behavior of these ferriheme complexes is summarized in Supporting Information Table S1. In each case, the appearance of the $4.2 \mathrm{~K}, 20 \mathrm{mT}$ Mössbauer spectrum is consistent with a combination of the shortest iron-iron distance and the number of iron neighbors within slightly more than $14 \AA$. The spin-spin relaxation model applied here does not take into account favorable pathways for electron spin relaxation, which in some cases may also contribute.

The specific structure of paral-[(TMP)Fe $\left(5-\mathrm{MeHIm}_{2}\right]_{\mathrm{ClO}}\left(\Delta \varphi=26^{\circ}, 30^{\circ}\right)^{55}$ and of [(TMP) $\mathrm{Fe}(1-\mathrm{MeIm})_{2} \mathrm{CClO}_{4}\left(\Delta \varphi=0^{\circ}\right),{ }^{54}$ each with two structurally slightly different $\mathrm{Fe}$ sites within the unit cell, also allows an alternative interpretation of the asymmetry in the line shapes of the doublets at $4.2 \mathrm{~K}$ and $20 \mathrm{mT}$ (Figures 3a and 4a, respectively): A superposition of two slightly different quadrupole splittings, each with symmetric line intensities and therefore each representing fast relaxation, also accounts for the observed asymmetric line patterns in Figures 3a and 4a. These fits are shown in Supporting Information Figures S7 and S8, together with 
the quadrupole splittings and isomer shifts of the two components used for the fits. Within this alternative model for fitting asymmetric quadrupole doublets, the group of complexes with $\Delta \varphi=0^{\circ}, 19.5^{\circ}$ and $26^{\circ}, 30^{\circ}$ exhibit fast relaxation at $4.2 \mathrm{~K}$ and $20 \mathrm{mT}$, the two complexes with $\Delta \varphi=70^{\circ}$ and $73.1^{\circ}$ exhibit intermediate relaxation and the complex with $\Delta \varphi=90^{\circ}$ exhibit slow relaxation. In summary, we note that in either of the two fitting procedures the relaxation process changes from fast relaxation for small angles $\Delta \varphi$ to intermediate relaxation for intermediate values of $\Delta \varphi$ and to slow relaxation for $\Delta \varphi=90^{\circ}$.

Unlike previous powdered samples of low-spin Fe(III) porphyrinates investigated by this group, ${ }^{72}$ the magnetic Mössbauer spectra of ground crystals of both paral-and perp[(OMTPP)Fe(1-MeIm) $\left.)_{2}\right] \mathrm{Cl}$ exhibit no contamination due to high-spin Fe(III), low-spin Fe(II) or other low-spin Fe(III) forms of either complex, and the spectra could be fit with only one component. This is probably due to the fact that all molecules in the sample have the same axial ligand plane orientations, whereas the previous samples, ${ }^{72}$ including those rapidlyprecipitated solid materials of possibly mixed crystalline forms as well as all frozen solution ${ }^{57} \mathrm{Fe}$-enriched samples, undoubtedly had a distribution of axial ligand plane dihedral angles. As shown below, in this work we find correlations between the axial ligand plane dihedral angle, $\Delta \varphi$, and the values of $g_{z z}, A_{z z}$ and $\Delta E_{Q}$, and thus it is not surprising that the magnetic Mössbauer spectra of poly-crystalline or frozen solution samples, which probably have a distribution of axial ligand plane dihedral angles, are not as easily fit.

The detailed results obtained in this work from the careful fitting of Mössbauer spectra in low $(20 \mathrm{mT})$ and high $(4.0$ and $7.0 \mathrm{~T})$ magnetic fields applied parallel and perpendicular to the direction of $\gamma$-beam for the six bis-imidazole and bis-pyridine complexes of Fe(III) OETPP, OMTPP and TMP are given in Table 1. In Table 2 the results of this study are summarized, along with EPR and magnetic Mössbauer data of other model heme complexes that were also acquired on the same crystalline form as used for the structure determinations; magnetic Mössbauer data acquired for the histamine complexes of nitrophorins 2 and $4^{86}$ are also included, as are available $\mathrm{EPR}^{37,39}$ and Mössbauer ${ }^{39}$ data for the $b c_{l}$ and $b_{6}$ protein complexes. As can be seen, the three "parallel" model ferriheme complexes have much larger quadrupole splittings than do the three "perpendicular" complexes. This result is consistent with previous studies, ${ }^{38,54,72}$ and is expected because the "parallel" complexes, with large rhombicity, should have much more asymmetric electron distributions than do the "perpendicular" complexes. Indeed, the "parallel" complexes show an asymmetry parameter $\eta \sim-2$ which means that by far the largest-magnitude component of the EFG, $V_{x x}$, is much larger than $V_{z z}$. The "perpendicular" complexes on the other hand show $\eta \sim-1$ which means that the magnitudes of $V_{x x}$ and $V_{z z}$ are similar.

The isomer shifts of the six complexes are within experimental error of each other and equal to $0.27(2) \mathrm{mm} / \mathrm{s}$, as is expected for low-spin Fe(III) complexes at $4.2 \mathrm{~K}$. The hyperfine coupling constants of the complexes are also consistent with those reported previously, $38,54,72$ with the largest-magnitude hyperfine coupling constant, $A_{z z}$, being considerably smaller for the "parallel" complexes (400-540 kG) than for the strictly perpendicular complex (902 kG), $A_{x \mathrm{x}}$ being negative for all six complexes and smallest in magnitude for the strictly perpendicular complex ( $-225 \mathrm{kG}$ ), and $A_{y y}$ being small and usually positive, but difficult to estimate with accuracy for all six complexes.

The structure, EPR and Mössbauer data for bis-imidazole- and bis-pyridine-coordinated OETPP-, OMTPP-, and TMPFe(III) complexes under study in this work, $38,54,86$ as well as other well-characterized systems reported previously, allow us to establish some interesting qualitative correlations of the values of $g_{z z}, A_{z z}$ or $\Delta E_{Q}$, with the dihedral angle between the axial ligands. In Figure 6 the values of $g_{z z}$ are plotted as a function of the dihedral angle, $\Delta \varphi$, and a linear correlation is observed: $g_{z z}$ increases with increasing $\Delta \varphi$. The $g_{z z}$-values of 
bovine cytochrome $b c_{l}$ hemes $b_{H}$ and $b_{L}$ and spinach chloroplast cytochrome $b_{6} f$ hemes $b_{h}$ and $b_{l}$ are also included in Figure 6 (data points 12 to 15, respectively). All these $g_{z z}$ values deviate somewhat from the least-squares fit of the model heme data points. Part of this deviation might possibly be a result of the difference between the substituents present on the natural heme (protohemin IX, heme $b$ ) and those used for the present study, all but one of which have phenyl substituents on the meso-carbons. However, the nitrophorin data points (4 and 6$)$ do not deviate significantly from the best-fit line, even though they also contain heme $b$. Preliminary DFT calculations 90 indicate no obvious dependence of Mössbauer parameters upon heme substituents. More likely, it should be noted that the $\mathrm{g}_{\max }$ signal for one of the $b$ ferrihemes of the $b c_{1}$ complex $\left(b_{H}\right)$, as well as those of several of the model ferrihemes (notably $9,54 \mathbf{1 0}^{49}$ and to a lesser extent $\mathbf{1 1}^{57}$ ) are broad, probably in part as a result of g-strain, 91 and in part as a result of a distribution of g-values arising from a degree of microheterogeneity in the structures of the ferriheme centers. ${ }^{37}$ For the $b c_{l}$ complex a range of g-values has been reported for each of the $b$ ferrihemes (3.41-3.4437 and as high as $3.48^{62}$ for ferriheme $b_{H}$ and 3.75-3.78 for ferriheme $b_{L}{ }^{37}$ ); the g-value reported for the two $b$ hemes of cytochrome $b_{6} f$ is an estimate based upon Mössbauer data, ${ }^{39}$ and it is possible that the individual values differ somewhat from this average. Therefore, in Figure 6 we have shown distributions of $g_{z z}$ values for both types of cytochrome $b$ heme centers and three of the model ferriheme complexes as well. The maximum possible g-value for a low-spin Fe(III) complex is about $3.8,37$ and ferriheme center $b_{L}(\mathbf{1 3})$ approaches that limit more closely than any other bisimidazole-coordinated ferriheme complex currently known; at present we do not know why the model ferrihemes with $89^{\circ}$ or $90^{\circ}$ dihedral angles do not have larger $g_{\max }$ values. One possible difference between the model ferrihemes and the large protein complexes is the electrostatic nature of the medium, a concentrated crystal lattice with closely-spaced cations and anions as compared to a generally hydrophobic intermembrane location for the cytochrome $b$ ferrihemes. However, the latter do have one arginine guanidinium side chain hydrogen-bonded to the two propionates of each heme $b^{14-26}$ (except for yeast $b_{H}$, where a lysine ammonium side chain plays this role 22 ), thus making the protohemin center neutrally-charged overall, and isolated by nearly $10 \AA$ between the heme edges of $b_{L}$ and $b_{H}$ or $b_{l}$ and $b_{h}$, or $20.2-20.9 \AA$ between Fe(III) centers. 14-27 As already mentioned above, in the crystalline model complexes of this study the closest distances between Fe(III) centers range from 9.5 to $12.7 \AA$ depending on crystal form (Supporting Information Table S2). How to evaluate the possible contributions of the difference in electrostatic medium to the observed EPR g-values is not clear at this time.

The synthetic complexes of the present study whose values of $g_{z z}$ deviate the most from this best-fit line have special structural features that may contribute to the deviation of their gvalues from the least-squares line for the other model complexes. Complex $\mathbf{5}$, paral-[(TMP) $\left.\mathrm{Fe}(5-\mathrm{MeHIm})_{2}\right]^{+}$, has one 5-MeHIm ligand $\mathrm{N}-\mathrm{H}$ hydrogen-bound to a lattice 5-MeHIm, and the other 5-MeHIm ligand N-H hydrogen-bound to an oxygen of the perchlorate anion, both of which makes the bound ligands more imidazolate-like (frozen solution samples yielded gvalues of 2.89, 2.31 and 1.58 for a Fe to 5-MeHIm ratio of $\sim 1: 2$. but 2.64, 2.30, 1.80 for a ratio of 1:60, where sufficient excess 5-MeHIm is available to act as hydrogen-bond acceptors from the bound 5-MeHIm ligands). ${ }^{55}$ Complex 3, paral-[(OMTPP)Fe(1-MeIm) $\left.)_{2}\right]^{+}$, has one Fe-N axial ligand bond significantly longer than the other (2.0155(19) as compared to $1.9747(19)$ $\AA$ ), and longer than in the case of other low-spin iron(III) porphyrinates, with the shorterbonded ligand being further off the heme normal $\left(9.1^{\circ}\right.$ than the longer-bonded ligand $\left(3.2^{\circ}\right.$. 57 The g-values of these two model ferriheme complexes, as well as the cytochrome $b$ and $b_{6} \mathrm{~g}$-values have not been included in the calculation of the least-squares line.

The correlation is better for the plot of $A_{z z}$ against $\Delta \varphi$ (Figure 7), except for the cyto-chrome $b_{6}$ data points $(\mathbf{1 4}, \mathbf{1 5})$; the deviation of the latter is mainly a consequence of the difficulty of fitting the magnetic Mössbauer spectra of complex systems consisting of overlapping broad spectra. The fact that both $g_{z z}$ and $A_{z z}$ are correlated with the dihedral angle, $\Delta \varphi$, is not 
surprising, because a correlation exists between $A_{z z}$ and $g_{z z}{ }^{72}$ Thus, it is a bit surprising that point 3 does not fall off the best-fit line of the plot of $A_{z z}$ vs. $\Delta \varphi$, as it does for the plot of $g_{z z}$ (and also $\Delta \mathrm{E}_{\mathrm{Q}}$, discussed below) vs. $\Delta \varphi$. In the case of $\mathbf{3}$, it is possible that this discrepancy might be a result of the choice of the fast-relaxation limit for analysis of the magnetic Mössbauer data for 3 . This choice is justified by the fact that we observe a symmetric doublet with no magnetic splitting at $4.2 \mathrm{~K}$ in a field of $20 \mathrm{mT}$ (Figure 5a). Nevertheless, we have also analyzed the $7 \mathrm{~T}$ spectra of $\mathbf{3}$ in the slow-relaxation limit, which reduces $\mathrm{A}_{\mathrm{zz}}$ from 499 to 450 $\mathrm{kG}$. However, within this limit of slow relaxation it was not possible to find a unique parameter set that also fits the spectra obtained at $4 \mathrm{~T}$. Therefore, we have reported the fast-relaxation limit fit for 3 in Table 1 and Figure 7; although the slow-relaxation limit value of $450 \mathrm{kG}$ would cause this data point to be off the correlation line, it would still deviate less than $\mathbf{1}$ and $\mathbf{1 1}$. In spite of the deviations, utilizing the correlations between $\Delta \varphi$ and $\mathrm{g}_{z z}$ or $A_{z z}$ we have a new method for obtaining structural information: By using Figure 6 and 7, unknown dihedral angles of ferriheme axial ligands may be roughly estimated by measuring $g_{z z}$ by EPR spectroscopy and/or (preferably) $A_{z z}$ by Mössbauer spectroscopy.

A linear correlation between $\Delta E_{Q}$ and $\Delta \varphi$ is less obvious (Figure 8), although in general Type $\mathrm{I}^{45}$ complexes with $\Delta \varphi \geqq 70^{\circ}$ show $\Delta E_{Q}$ less than or approximately equal to $2.1 \mathrm{~mm} / \mathrm{s}$ and Type $\mathrm{II}^{45}$ complexes have $\Delta E_{Q}$ values in the range from 2.2 to as large as $2.8 \mathrm{~mm} / \mathrm{s}$. We have checked to see whether off-axis binding of axial ligands, or small vs. large angles between axial ligands and the N-Fe-N porphyrin axes may affect the Mössbauer parameters obtained, but from the data summarized in Supporting Information Table S2, no dependence of the parameters on these factors is obvious: The largest deviations from the plots of $g_{z z}$ and $\Delta E_{Q}$ (there are no large deviations from the plot of $A_{z z}$ ) vs. axial ligand plane dihedral angle, $\Delta \varphi$, are for $\mathbf{3}$ (paral-[(OMTPP)Fe(1-MeIm) $\left.{ }_{2}\right]^{+}$) and $\mathbf{5}$ (paral-[(TMP)Fe $\left.(5-\mathrm{MeHIm})_{2}\right]^{+}$, and while 3 does have a large deviation of one ligand from the heme normal $\left(9.1^{\circ}, \mathbf{5}\right.$ does not $\left(4.0^{\circ}\right.$ and $6.8^{\circ}$ for one ligand of each of the two molecules in the unit cell of 5 ), and the largest deviations from the heme normal $\left(10^{\circ}, 12^{\circ} ; 10.6^{\circ}\right.$; and $12.2^{\circ}$ are exhibited by $\mathbf{6}$ (NP4-histamine), 10 ([(TPP) $\left.\mathrm{Fe}(2-\mathrm{MeHIm})_{2}\right]^{+}$, and 7 ([(OETPP)Fe $\left.\left.\left(4-\mathrm{Me}_{2} \mathrm{NPy}\right)_{2}\right]^{+}\right)$, respectively, for which the correlations of $g_{z z}$ and $\Delta E_{Q}$ with $\Delta \varphi$ do not deviate significantly from the least-squares line (Figures 6 and 8).

Thus, the Mössbauer and EPR parameters for bis-imidazole and bis-pyridine Fe(III) porphyrins of this study, as well as those of other $\left(\mathrm{d}_{\mathrm{xy}}\right)^{2}\left(\mathrm{~d}_{\mathrm{xz}}, \mathrm{d}_{\mathrm{yz}}\right)^{3}$ ground state systems included in Table 2 and Figures $6^{-8}$, are part of a continuum that appears to exist for Type I and Type II complexes, except that so far there are data for complexes having axial ligand plane dihedral angles between $30^{\circ}$ and $70^{\circ}$. The recent solution of three structures of $\left[(\mathrm{OETPP}) \mathrm{FeL}_{2}\right]^{+}$complexes where $\mathrm{L}=$ imidazole, 1-benzylimidazole, and 1-methylimidazole, however, appears to fill that gap with molecules having ligand plane dihedral angles ranging from $16.0^{\circ}$ to $30.3^{\circ}$ to $44.6^{\circ}$ to $56.8^{\circ}$ to $57.2^{\circ}$ to $59.6^{\circ}$ to $88.1^{\circ} .9^{9}$ The smaller four dihedral angle centers give rise to normal rhombic EPR spectra, while the largest three dihedral angle centers give rise to "large $g_{\text {max }}$ " EPR spectra. 92 From this group of molecular structures it thus appears that the transition from normal rhombic to "large $g_{\max }$ " is sharp and occurs at an axial ligand plane dihedral angle of $57^{\circ} .{ }^{9}$ However, no Mössbauer spectra have yet been obtained on these new crystalline forms to allow us to evaluate trends in $A_{z z}$ and $\Delta E_{Q}$.

From the present study we can reach conclusions about the extremes in axial ligand plane dihedral angles, from $0^{\circ}$ to $30^{\circ}$ and $70^{\circ}$ to $90^{\circ}$ : The perp-[(OMTPP $\left.) \mathrm{Fe}(1-\mathrm{MeIm})_{2}\right] \mathrm{Cl}(\Delta \varphi=$ $90^{\circ}$ has a value of $A_{z z}$ that is among the largest reported thus far, ${ }^{72}$ and similar to that of cytochrome $b_{6}$ of chloroplasts, ${ }^{39}$ heme $c$ of Thiobacillus denitrificans cytochrome $c d_{1}$ nitrite reductase, 67 and low-spin heme $c$ (1) of Desulfovibrio desulfuricans hexaheme nitrite reductase $^{69}\left(926,910,926 \mathrm{kG}\right.$, respectively). Paral-[(TMP) $\left.\mathrm{Fe}(5-\mathrm{MeHIm})_{2}\right] \mathrm{ClO}_{4}$, paral$\left[(\mathrm{OMTPP}) \mathrm{Fe}(1-\mathrm{MeIm})_{2}\right] \mathrm{Cl}$, and $\left[(\mathrm{TMP}) \mathrm{Fe}(1-\mathrm{MeIm})_{2}\right] \mathrm{ClO}_{4}$ have values of $A_{z z}$ that are typical 
of complexes known to have axial ligands in strictly or at least nearly parallel planes, including $\left[(\mathrm{OEP}) \mathrm{Fe}\left(4-\mathrm{Me}_{2} \mathrm{NPy}\right)_{2}\right] \mathrm{ClO}_{4}, 54\left[(\mathrm{OEP}) \mathrm{Fe}(1-\mathrm{MeIm})_{2}\right] \mathrm{ClO}_{4}, 71\left[\left(\left((\mathrm{OMe})_{2}\right)_{4} \mathrm{TPP}\right) \mathrm{Fe}(1-\right.$ $\left.\mathrm{MeIm})_{2}\right]^{+} 72$ and $\left[\left(\left((\mathrm{OMe})_{2}\right)_{4} \mathrm{TPP}\right) \mathrm{Fe}\left(4-\mathrm{NMe}_{2} \mathrm{Py}\right)_{2}\right]^{+72}$ among model hemes $(446,550,530$, $500 \mathrm{kG}$, respectively) and low-spin hemes $c$ (4) and (5) of Desulfovibrio desulfuricans hexaheme nitrite reductase ${ }^{69}(540,505 \mathrm{kG}$, respectively) and nitrophorins 2 and 4 (530, 540 $\mathrm{kG}$, respectively $86,{ }^{93-95}$ among heme proteins. It would be interesting to carry out a magnetic Mössbauer spectroscopic investigation of mitochondrial Complex III, but because the cytochrome $b c_{1}$ complex contains three heme centers, all with "large $\mathrm{g}_{\max }$ " EPR signals, 37 deconvolution of the three overlapping spectra with likely similar values of $A_{z z}$ would be extremely difficult without using redox poising of several Mössbauer samples, as has been done to deconvolute the EPR signals, 37 and even then there would still be spectral overlap, as was true in the case of the Mössbauer spectra of chloroplast $b_{6} f .39$

\section{Conclusions.}

We have shown that relationships exist between increasing dihedral angle of the axial ligand planes, $\Delta \varphi$ (from $0^{\circ}$ to $90^{\circ}$ ), and Mössbauer spectroscopic properties. $A_{z z}$ dominates the magnetic splitting of the Mössbauer spectra exhibiting "large g gax " EPR signals (Type I complexes). The values of $g_{z z}$ and $A_{z z}$ increase with increasing dihedral angle (Figure 6 and 7 ), which means that the hyperfine field $\mathbf{B}_{\mathrm{hf}}$ is greatest for perpendicular ligand plane orientation. In contrast, the quadrupole splitting behaves oppositely, decreasing with growing dihedral angle (Figure 8). In general, the "parallel" complexes show asymmetry parameters $\eta$ near -2, which means that the largest-magnitude component of the EFG, $V_{x x}$, is much greater than $V_{z z}$, while the "perpendicular" complexes show $\eta$ near -1, which means that the magnitudes of $V_{x x}$ and $V_{z z}$ are similar. Thus, an increasing dihedral angle of the ligand planes leads to a smaller distortion of the charge density at the iron center.

\section{Supplementary Material}

Refer to Web version on PubMed Central for supplementary material.

\section{Acknowledgements}

Acknowledgements. We thank the National Institutes of Health, Grant DK-31038 (FAW), and Grant GM-38401 (WRS), and the Deutsche Forschungsgemeinschaft (AXT) for support of this research. This paper was written while FAW was on Sabbatical leave in the Institut für Physik, Universität zu Lübeck with support from an Alexander von Humboldt Senior Award in Science, and is dedicated to Prof. Philipp Gütlich on the occasion of his $70^{\text {th }}$ birthday.

\section{References}

1. Mathews, FS.; Czerwinski, EW.; Argos, P. The Porphyrins. Dolphin, D., editor. VII. Academic Press; New York: 1979. p. 108-147.

2. Lederer F, Ghrir R, Guiard B, Cortial S, Ito A. Eur. J. Biochem 1983;132:95-102. [PubMed: 6840088]

3. Pierrot M, Haser R, Frey M, Payan F, Astier J-P. J. Biol. Chem 1982;257:14341-14348. [PubMed: 6292223]

4. Higuchi Y, Kusunoki M, Matsuura Y, Yasuoka N, Kakudo M. J. Mol. Biol 1984;172:109-139. [PubMed: 6319712]

5. Simões P, Matias PM, Morais J, Wilson K, Dauter Z, Carrondo MA. Inorg. Chim. Acta 1998;273:213224.

6. Nørager S, Legrand P, Pieulle L, Hatchikian C, Roth M. J. Mol. Biol 1999;290:881-902. [PubMed: 10398589]

7. Brennan L, Turner DL, Fareleira P, Santos H. J. Mol. Biol 2001;308:353-365. [PubMed: 11327772]

8. Hamada K, Bethge PH, Mathews FS. J. Mol. Biol 1995;247:947-962. [PubMed: 7723042]

9. Timkovich, R. The Porphyrins. Dolphin, D., editor. 12. Academic Press; NY: 1979. p. 241-294. 
10. Iverson TM, Luna-Chavez C, Cecchini G, Rees DC. Science 1999;284:1961-1966. [PubMed: 10373108]

11. Lancaster CRD, Kröger A, Auer M, Michel H. Nature 1999;402:377-385. [PubMed: 10586875]

12. Lancaster CRD. Biochim. Biophys. Acta 2002;1553:1-6. [PubMed: 11803013]

13. Yankovskaya V, Horsefield R, Törnroth S, Luna-Chavez C, Miyoshi H, Léger C, Byrne B, Cecchini G, Iwata S. Science 2003;299:700-704. [PubMed: 12560550]

14. Xia D, Yu C-A, Kim H, Xia J-Z, Kachurin AM, Zhang L, Yu L, Deisenhofer J. Science 1997;277:6066. [PubMed: 9204897]

15. Iwata S, Lee JW, Okada K, Lee JK, Iwata M, Rasmussen B, Link TA, Ramaswamy S, Jap BK. Science 1998;281:64-71. [PubMed: 9651245]

16. Zhang, Zh.; Huang, L.; Shulmeister, VM.; Chi, Y-I.; Kim, KK.; Hung, L-W.; Crofts, AR.; Berry, EA.; Kim, S-H. Nature 1998;392:677-684. [PubMed: 9565029]

17. Hunte C, Koepke J, Lange C, Rossmanith T, Michel H. Structure 2000;8:669-684. [PubMed: 10873857]

18. Lange C, Nett JH, Trumpower BL, Hunte C. EMBO J 2001;20:6591-6600. [PubMed: 11726495]

19. Lange C, Hunte C. Proc. Natl. Acad. Sci. U.S.A 2002;99:2800-2805. [PubMed: 11880631]

20. Gao X, Wen X, Yu C, Esser L, Tsao S, Quinn B, Zhang L, Yu L, Xia D. Biochemistry 2002;41:1169211702. [PubMed: 12269811]

21. Gao X, Wen X, Esser L, Quinn B, Yu L, Yu C-A, Xia D. Biochemistry 2003;42:9067-9080. [PubMed: 12885240]

22. Palsdottir H, Lojero CG, Trumpower BL, Hunte C. J. Biol. Chem 2003;278:31303-31311. [PubMed: 12782631]

23. Berry EA, Huang L-S, Saechao LK, Pon NG, Valkova-Valchanova M, Daldal F. Photosynth. Res 2004;81:251-275. [PubMed: 16034531]

24. Huang L, Cobessi D, Tung E. Y.; Berry, E. A. J. Mol. Biol 2005;351:573-597.

25. Stroebel D, Choquet Y, Popot J-L, Picot D. Nature 2003;426:413-418. [PubMed: 14647374]

26. Durisu G, Zhang H, Smith JL, Cramer WA. Science 2003;302:1009-1014. [PubMed: 14526088]

27. Cramer WA, Zhang H, Yan J, Kurisu G, Smith JL. Biochemistry 2004;43:5921-5929. [PubMed: 15147175]

28. Michel H, Behr J, Harrenga A, Kannt A. Annu. Rev. Biophys. Biomol. Struct 1998;27:329-356. [PubMed: 9646871]

29. Einsle O, Messerschmidt A, Stach P, Bourenkov GP, Bartunik HD, Huber R, Kroneck PMH. Nature 1999;400:476-480. [PubMed: 10440380]

30. Einsle O, Stach P, Messerschmidt A, Simon J, Kröger A, Huber R, Kroneck PMH. J. Biol. Chem 2000;275:39608-39616. [PubMed: 10984487]

31. Jafferji A, Allen JWA, Ferguson JJ, Fülöp V. J. Biol. Chem 2000;275:25089-25094. [PubMed: 10827177]

32. Jormakka M, Törnroth S, Byrne B, Iwata S. Science 2002;295:1863-1868. [PubMed: 11884747]

33. Crane BR, Siegel LM, Getzoff ED. Science 1995;270:59-67. [PubMed: 7569952]

34. Smith JL, Zhang H, Yan J, Kurisu G, Cramer WA. Curr. Opin. Struct. Biol 2004;14:432-439. [PubMed: 15313237]

35. Breyton C. Biochim. Biophys. Acta 2000;1459:467-474. [PubMed: 11004464]

36. Orme-Johnson NR, Hansen RE, Beinert H. Biochem. Biophys. Res. Commun 1974;45:871-878. [PubMed: 4330143]

37. Salerno JC. J. Biol. Chem 1984;259:2331-2336. [PubMed: 6321467]

38. Walker FA, Huynh BH, Scheidt WR, Osvath SR. J. Am. Chem. Soc 1986;108:5288-5297.

39. Schünemann V, Trautwein AX, Illerhaus J, Haehnel W. Biochemistry 1999;38:8981-8991. [PubMed: 10413471]

40. T'sai A-L, Palmer G. Biochim. Biophys. Acta 1982;681:484-495. [PubMed: 6289886]

41. Salerno JC, McGill JW, Gerstle GC. FEBS Lett 1983;162:257.

42. Salerno JC, Yoshida S, King TE. J. Biol. Chem 1986;261:5480-5486. [PubMed: 3007507] 
43. Walker FA, Reis D, Balke VL. J. Am. Chem. Soc 1984;106:6888-6898.

44. Innis D, Soltis SM, Strouse CE. J. Am. Chem. Soc 1988;110:5644-5650.

45. Walker FA. Coord. Chem. Rev 1999;185-186:471-534.

46. Walker FA. Chem. Rev 2004;104:589-615. [PubMed: 14871136]

47. Carter KR, T'sai A-L, Palmer G. FEBS Lett 1981;132:243-246. [PubMed: 6271592]

48. Migita CT, Iwaizumi MJ. Am. Chem. Soc 1981;103:4378-4381.

49. Scheidt WR, Kirner JF, Hoard JL, Reed CA. J. Am. Chem. Soc 1987;109:1963-1968.

50. Walker, FA. In The Porphyrin Handbook. Kadish, KM.; Smith, KM.; Guilard, R., editors. 5. Academic Press; San Diego, CA: 2000. p. 81-183.Chapter 36

51. Ikeue T, Ohgo Y, Saitoh T, Yamaguchi T, Nakamura M. Inorg. Chem 2001;40:3423-3434. [PubMed: 11421688]

52. Martinez SE, Huang D, Ponomarev M, Cramer WA, Smith JL. Protein Sci 1996;5:1081-1092. [PubMed: 8762139]

53. Safo MK, Gupta GP, Walker FA, Watson CT, Simonis U, Scheidt WR. J. Am. Chem. Soc 1992;114:7066-7075.

54. Safo MK, Gupta GP, Walker FA, Scheidt WR. J. Am. Chem. Soc 1991;113:5497-5510.

55. Munro OQ, Serth-Guzzo JA, Turowska-Tyrk I, Mohanrao K, Shokhireva T. Kh. Walker FA, Debrunner PG, Scheidt WR. J. Am. Chem. Soc 1999;121:11144-11155.

56. Ogura H, Yatsunyk L, Medforth CJ, Smith KM, Barkigia KM, Renner MW, Melamed D, Walker FA. J. Am. Chem. Soc 2001;123:6564-6578. [PubMed: 11439043]

57. Yatsunyk L, Carducci MD, Walker FA. J. Am. Chem. Soc 2003;125:15986-16005. [PubMed: 14677991]

58. Protein Data Bank filenames 2AO6, 1PPJ, 1PP9, ${ }^{24}$ deposited June, 2005.

59. Schütz M, Schoepp-Cothenet B, Lojou E, Woodstra M, Lexa D, Tron P, Dolla A, Durand M-C, Stetter KO, Baymann F. Biochemistry 2003;42:10800-10808. [PubMed: 12962505]

60. It should be noted that in several previous publications, ${ }^{46,56,57}$ the EPR g-values of cytochromes $\mathrm{b}_{\mathrm{L}}$ and $\mathrm{b}_{\mathrm{H}}$ were inadvertently reversed.

61. Howell N, Robertson DE. Biochemistry 1993;32:11162-11172. [PubMed: 8218179]

62. Salerno JC, Xu Y, Osgood MP, Kim CH, King TE. J. Biol. Chem 1989;264:15398-15403. [PubMed: 2549062]

63. Sharrock M, Debrunner PG, Schulz C, Lipscomb JD, Marshall V, Gunsalus IC. Biochim. Biophys. Acta 1976;420:8-26. [PubMed: 2296]

64. Huynh BH, Emptage MH, Münck E. Biochim. Biophys. Acta 1978;534:295-306. [PubMed: 208633]

65. Dwivedi A, Toscano WA, Debrunner PG. Biochim. Biophys. Acta 1979;576:502-508. [PubMed: 218635]

66. Rhynard D, Lang G, Spartalian K, Yonetani T. J. Chem. Phys 1979;71:3715-3721.

67. Huynh BH, Lui MC, Moura JJG, Moura I, Ljungdahl PO, Münck E, Payne WJ, Peck HD, DerVartanian DV, LeGall J. J. Biol. Chem 1982;257:9576-9581. [PubMed: 6286626]

68. Debrunner, P. G. In Iron Porphyrins Lever, ABP.; Gray, HB., editors. VCH; Weinheim, Germany: 1989. p. 137-227.Part 3

69. Costa C, Moura JJG, Moura I, Liu MY, Peck HD, LeGall J, Wang Y, Huynh BH. J. Biol. Chem 1990;265:14382-14387. [PubMed: 2167315]

70. Schünemann V, Raitsimring AM, Benda R, Trautwein AX, Shokhireva T. Kh. Walker FA. J. Biol. Inorg. Chem 1999;4:709-716.

71. Benda R, Schünemann V, Trautwein AX, Walker FA. Israel J. Chem 2000;40:9-14.

72. Benda R, Schünemann V, Trautwein AX, Cai S, Polam JR, Watson CT, Shokhireva T. Kh. Walker FA. J. Biol. Inorg. Chem 2003;42:787-801. [PubMed: 12898323]

73. Polam JR, Wright JL, Christensen KA, Walker FA, Flint H, Winkler H, Grodzicki M, Trautwein AX. J. Am. Chem. Soc 1996;118:5272-5276.

74. Grodzicki M, Flint H, Winkler H, Walker FA, Trautwein AX. J. Phys. Chem. A 1997;101:42024207.

75. Hu C, Noll BC, Schulz CE, Scheidt WR. Inorg. Chem 2005;44:4346-4358. [PubMed: 15934765] 
76. Raitsimring AM, Borbat P, Shokhireva T. Kh. Walker FA. J. Phys. Chem 1996;100:5235-5244.

77. Astashkin AV, Raitsimring AM, Walker FA. J. Am. Chem. Soc 2001;123:1905-1913. [PubMed: 11456811]

78. Blumberg WE, Peisach J. Adv. Chem. Ser 1971;100:271-291.

79. Peisach J, Blumberg WE, Adler AD. Ann. N. Y. Acad. Sci 1973;206:310-327. [PubMed: 4356182]

80. Taylor CPS. Biochim. Biophys. Acta 1977;491:137-149. [PubMed: 191085]

81. Palmer G. Biochem. Soc. Trans 1985;13:548-560. [PubMed: 2993061]

82. Two molecules are found in the unit cell, one with an axial ligand plane dihedral angle of $26^{\circ}$ and the other of $30^{\circ}$, but the two have similar angles $\varphi$ from the N-Fe-N axes. ${ }^{55}$ Al-though there is evidence of two overlapping EPR spectra, it was not possible to deconvo-lute the two because of the similarity of the g-values. 55

83. Trautwein AX, Bill E, Bominaar EL, Winkler H. Struct. Bonding 1991;78:1-95.

84. Oosterhuis WT, Lang G. Phys. Rev 1969;178:439-456.

85. Griffith JS. Mol. Phys 1971;21:135-139.

86. Wegner P, Benda R, Schünemann V, Trautwein AX, Berry RE, Balfour CA, Wert D, Walker FA. Proceedings of the International Conference on the Applications of the Mössbauer Effect (ICAME 2001). Hyperfine Interact. C 2002;5:253-256.

87. Wegner, P. Ph.D. dissertation, Universität zu Lübeck. 2004.

88. Simonneaux G, Schünemann V, Morice C, Carel L, Toupet L, Winkler H, Trautwein AX, Walker FA. J. Am. Chem. Soc 2000;122:4366-4377.

89. Clauser MJ, Blume M. Phys. Rev. B 1971;3:583-591.

90. Teschner T, Paulsen H, Schuenemann V, Walker FA, Trautwein AX. Unpublished work

91. De Vries S, Albracht SP. J. Biochim. Biophys. Acta 1979;546:334-340.

92. Yatsunyk L, Dawson A, Carducci MD, Walker FA. J. Am. Chem. Soc. 2005;(June)Submitted for publication

93. The crystal structure of nitrophorin 4 (NP4) bound to the imidazole nitrogens of histidine-59 and exogenous histamine $(\mathrm{Hm})$, has been solved and shown to have an imidazole plane dihedral angle of $32^{\circ} .{ }^{94}$ Likewise, detailed ${ }^{1} \mathrm{H}$ and ${ }^{13} \mathrm{C}$ NMR investigations have shown that the imidazole plane dihedral angle for the histamine complex of NP2 is $24^{\circ} .95$

94. Roberts SA, Weichsel A, Qin Y, Shelnutt JA, Walker FA, Montfort WR. Biochemistry 2001;40:11327-11337. [PubMed: 11560480]

95. Shokhireva, T. Kh.; Smith, KM.; Andersen, JF.; Weichsel, A.; Balfour, C.; Montfort, WR.; Walker, FA. To be submitted 


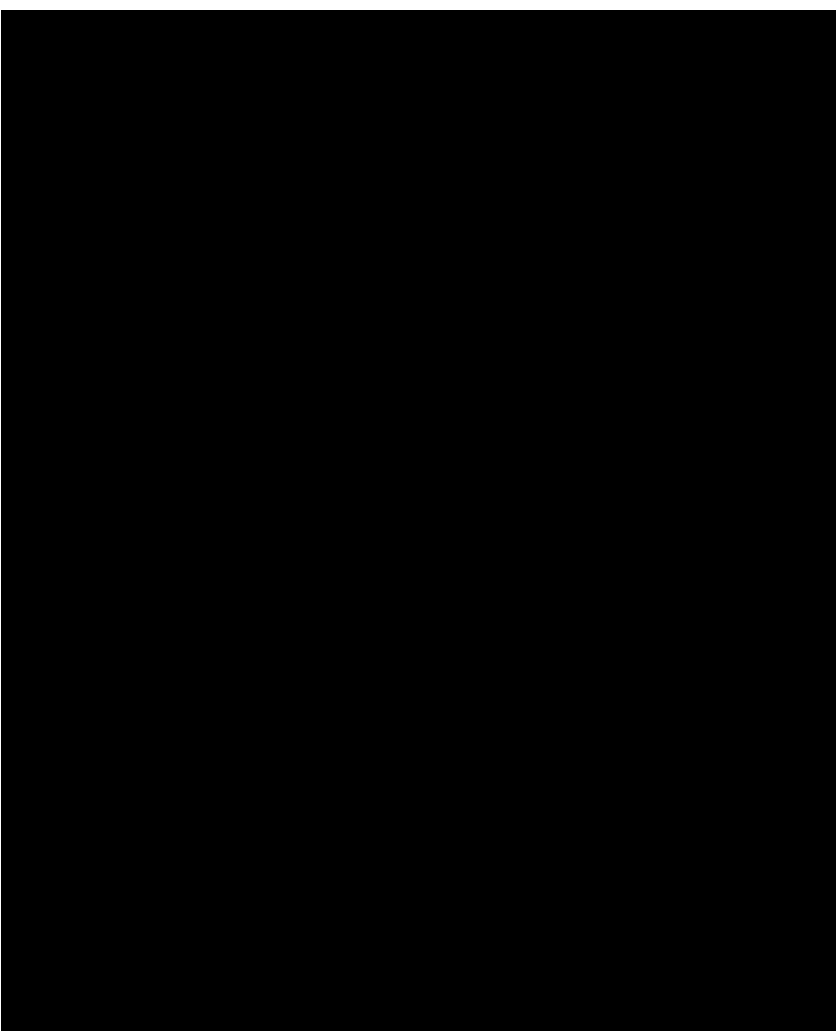

Figure 1.

Mössbauer spectra of perp-[(OMTPP)Fe $\left.(1-\mathrm{MeIm})_{2}\right] \mathrm{Cl}\left(\Delta \varphi=90^{\circ}\right)$ obtained at $4.2 \mathrm{~K}$ in the presence of several different magnetic fields applied perpendicular to the $\gamma$-beam (20 mT (a), $4 \mathrm{~T}$ (b) and $7 \mathrm{~T}(\mathrm{c})$ ). The solid lines are fits performed in the limit of slow relaxation with parameters given in Table 1. 


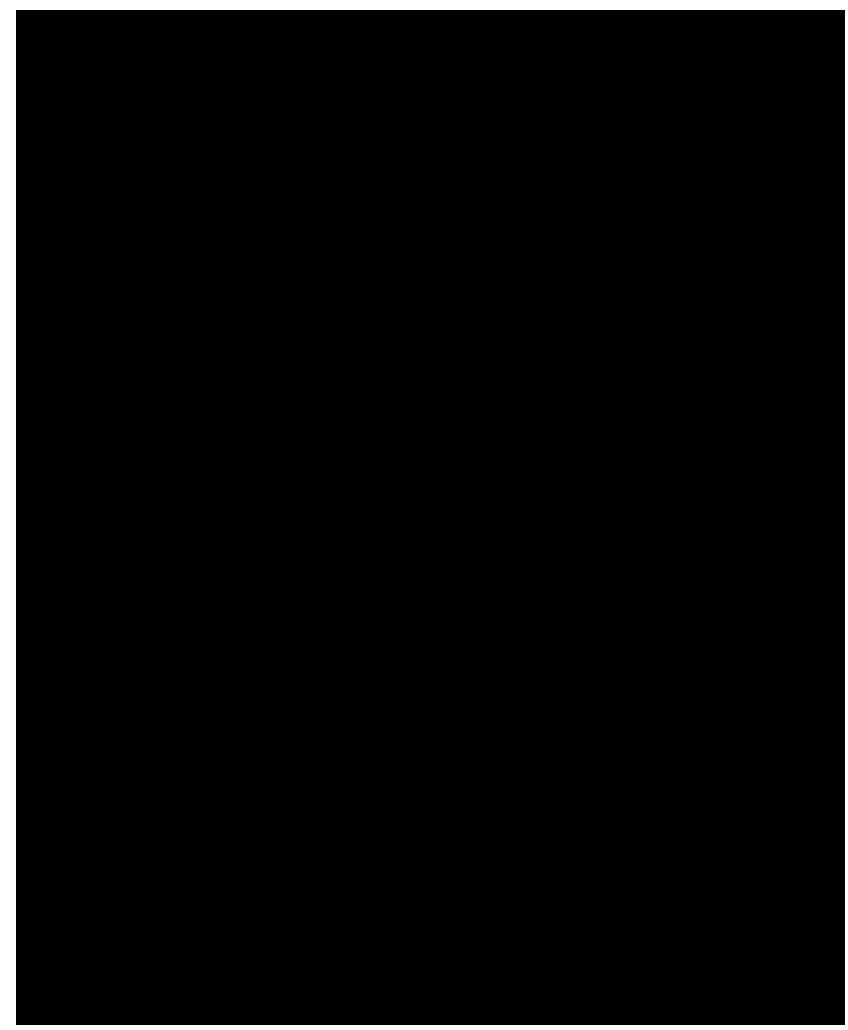

Figure 2.

Mössbauer spectra of perp-[(OETPP)Fe(1-MeIm) $\left.)_{2}\right] \mathrm{Cl}\left(\Delta \varphi=73.1^{\circ}\right)$ recorded at $4.2 \mathrm{~K}$ in the presence of several different magnetic fields applied perpendicular to the $\gamma$-beam (20 mT (a), $4 \mathrm{~T}$ (b), and $7 \mathrm{~T}$ (c)). The solid line in the spectrum recorded at $20 \mathrm{mT}$ (a) is a fit taking spinspin relaxation effects (with relaxation rate $\omega=0.47 \cdot 10^{8} \mathrm{~Hz}$ ) into account, ${ }^{89}$ and the other solid lines (4 T (b) and $7 \mathrm{~T}$ (c)) are fits performed in the limit of slow relaxation with parameters given in Table 1. 


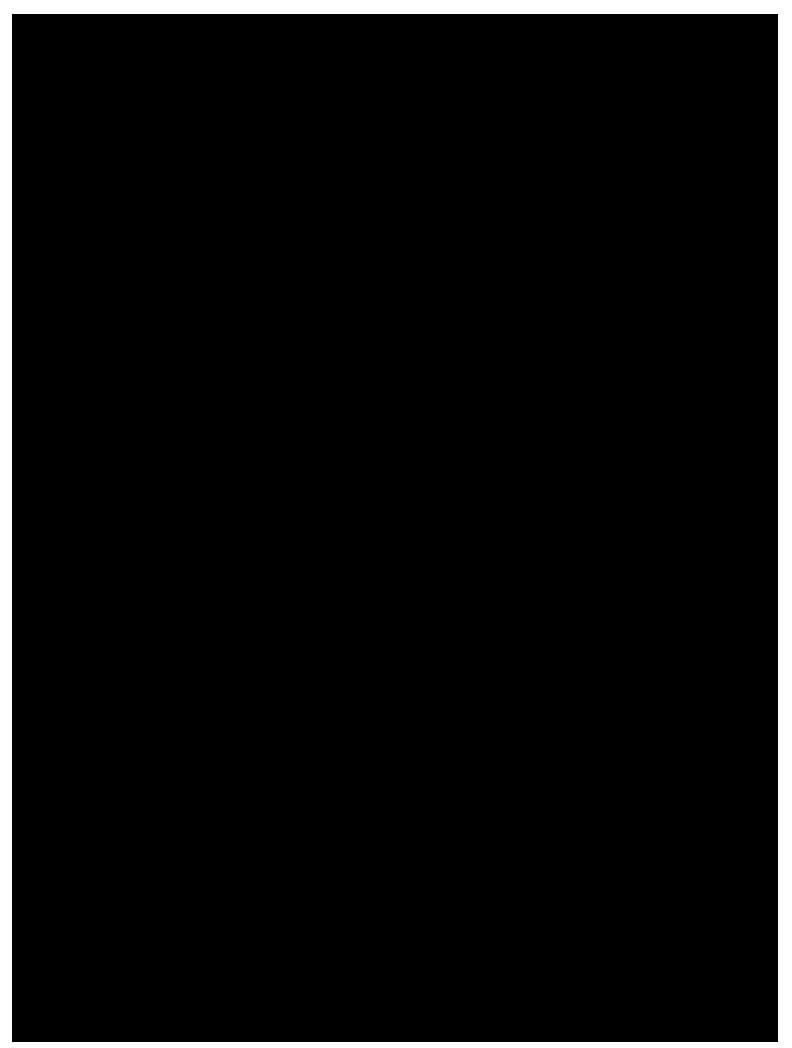

Figure 3.

Mössbauer spectra of paral-[(TMP)Fe(5-MeHIm $\left.)_{2}\right] \mathrm{ClO}_{4}\left(\Delta \varphi=26^{\circ}, 30^{\circ}\right)^{82}$ taken at $4.2 \mathrm{~K}$ in the presence of several different magnetic fields applied perpendicular to the $\gamma$-beam as indicated. The solid line in the spectrum recorded at $20 \mathrm{mT}$ (a) is a fit taking spin-spin relaxation effects (with $\omega=1.42 \cdot 10^{8} \mathrm{~Hz}$ ) into account, ${ }^{89}$ while the other solid lines (for (b) and (c)) are fits performed in the limit of slow relaxation with parameters given in Table 1. 


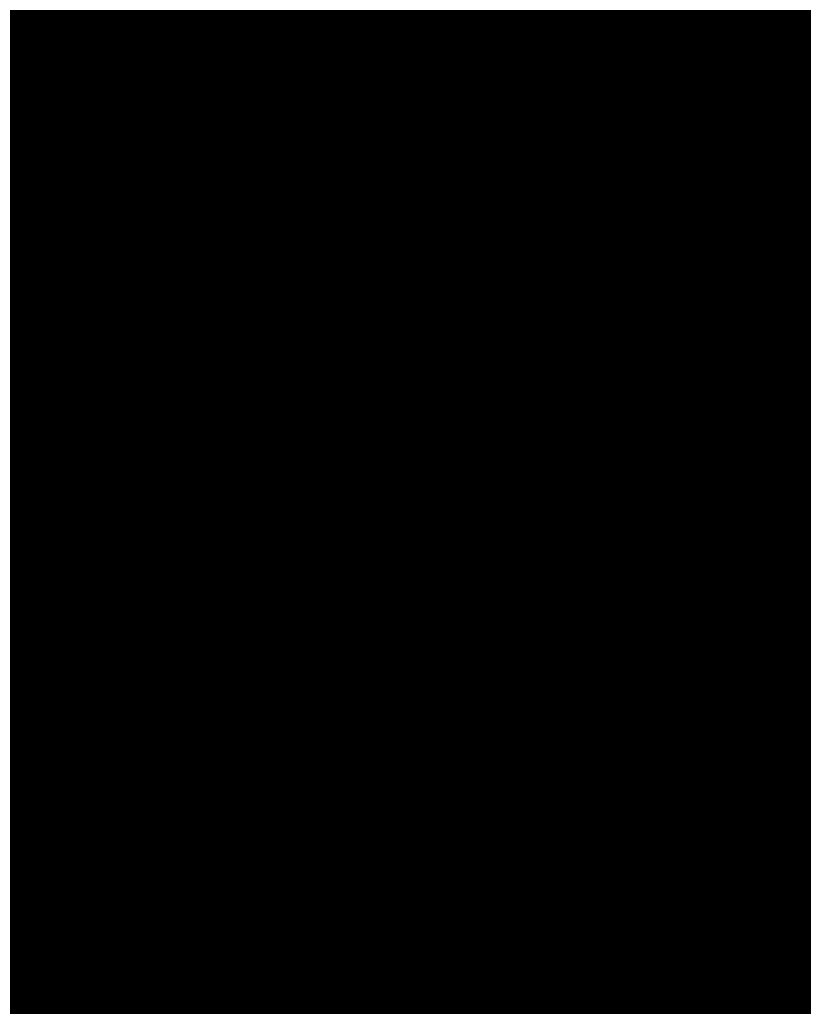

Figure 4.

Mössbauer spectra of $\left[(\mathrm{TMP}) \mathrm{Fe}(1-\mathrm{MeIm})_{2}\right] \mathrm{ClO}_{4}\left(\Delta \varphi=0^{\circ}\right)$ recorded at $4.2 \mathrm{~K}$ in the presence of several different magnetic fields applied perpendicular to the $\gamma$-beam as indicated. The solid line in the spectrum recorded at $20 \mathrm{mT}$ (a) is a fit taking spin-spin relaxation effects (with $\omega=$ $0.81 \cdot 10^{8} \mathrm{~Hz}$ ) into account, ${ }^{89}$ while the other solid lines ((b) and (c)) are fits performed in the limit of slow relaxation with parameters given in Table 1. 


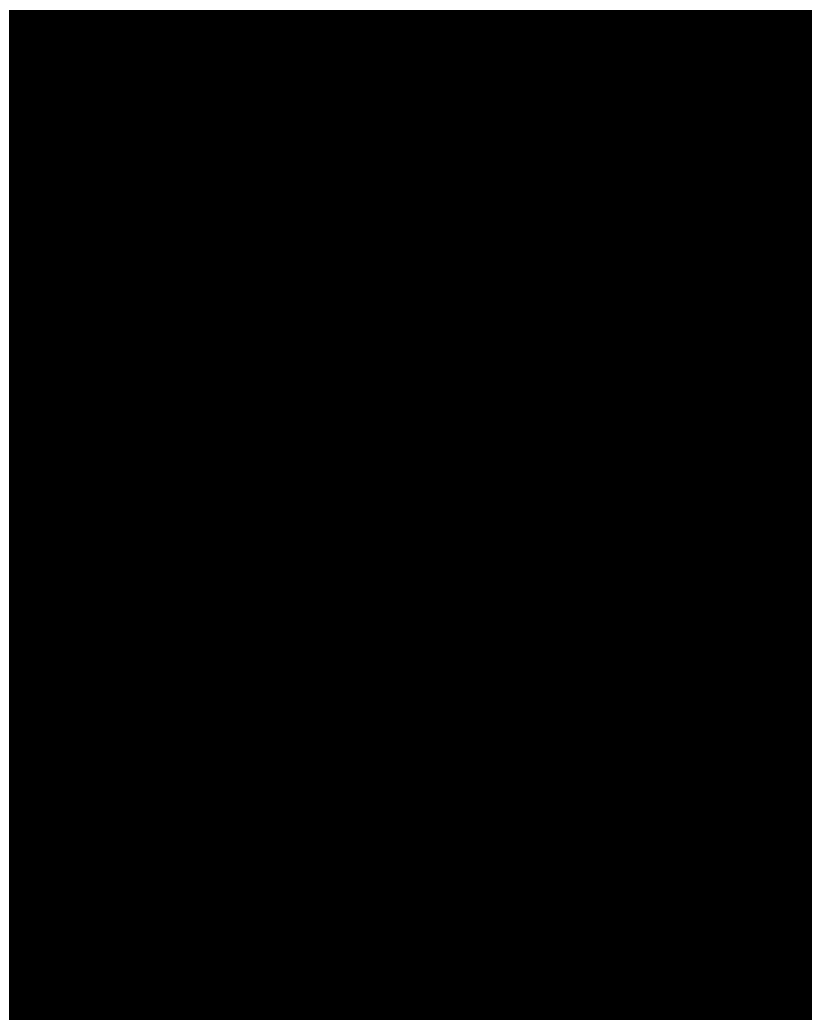

Figure 5.

Mössbauer spectra of paral-[(OMTPP)Fe $\left.(1-\mathrm{MeIm})_{2}\right] \mathrm{Cl}\left(\Delta \varphi=19.5^{\circ}\right)$ obtained at $4.2 \mathrm{~K}$ in the presence of several different magnetic fields applied perpendicular to the $\gamma$-beam as indicated. The solid lines are fits performed in the limit of fast relaxation with parameters given in Table 1 . 


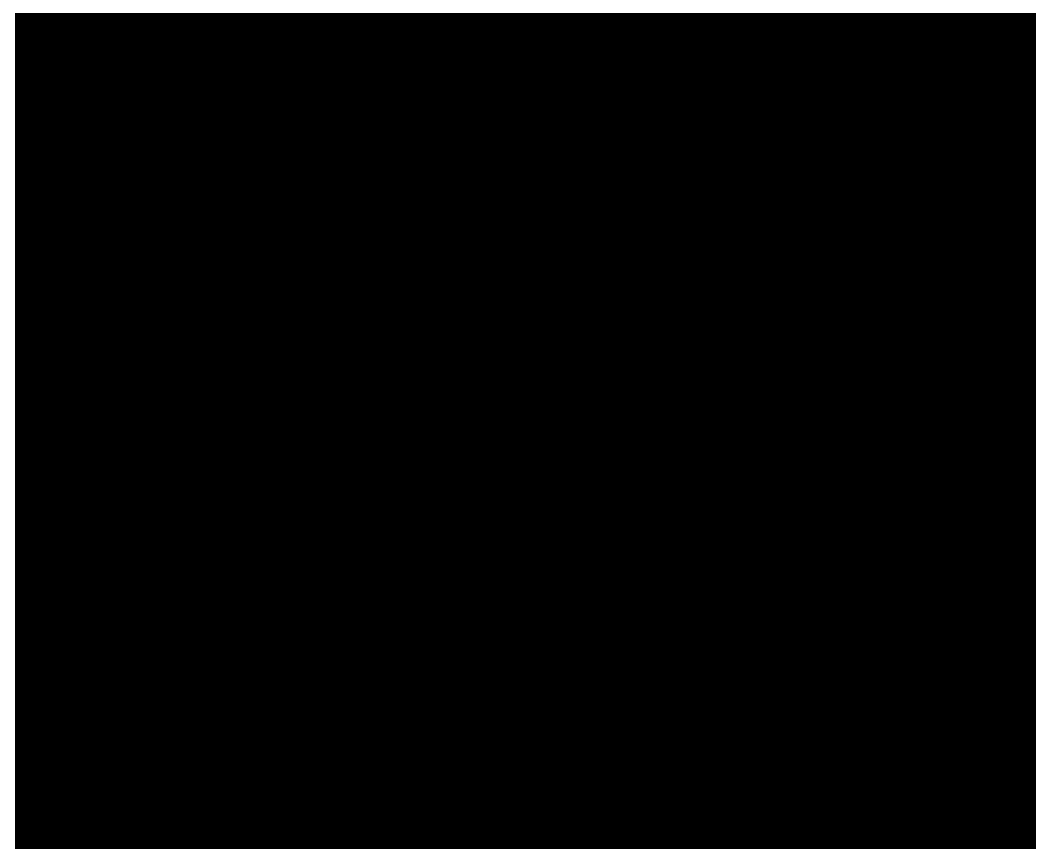

Figure 6.

Correlation of $g_{z z}$ with dihedral angle of the axial ligand planes, $\Delta \varphi$. Denotation of the complexes is given in Table 2. Large $g_{\max }$ ferriheme centers often have broad signals, which are represented in this figure as a range of g-values. For chloroplast cytochrome $b_{6}$ hemes $(\mathbf{1 4}, \mathbf{1 5})$, Mössbauer spectra yielded $\mathrm{g}_{\mathrm{zz}}=3.6$ for both $b_{h}$ and $b_{l},{ }^{39}$ but it is possible that the two have somewhat different g-values, as indicated by the ranges shown for each. The data points for model heme complexes 3 and $\mathbf{5}$ and the protein complexes $\mathbf{1 2}$ - $\mathbf{1 5}$ are not included in calculation of the least-squares line. 


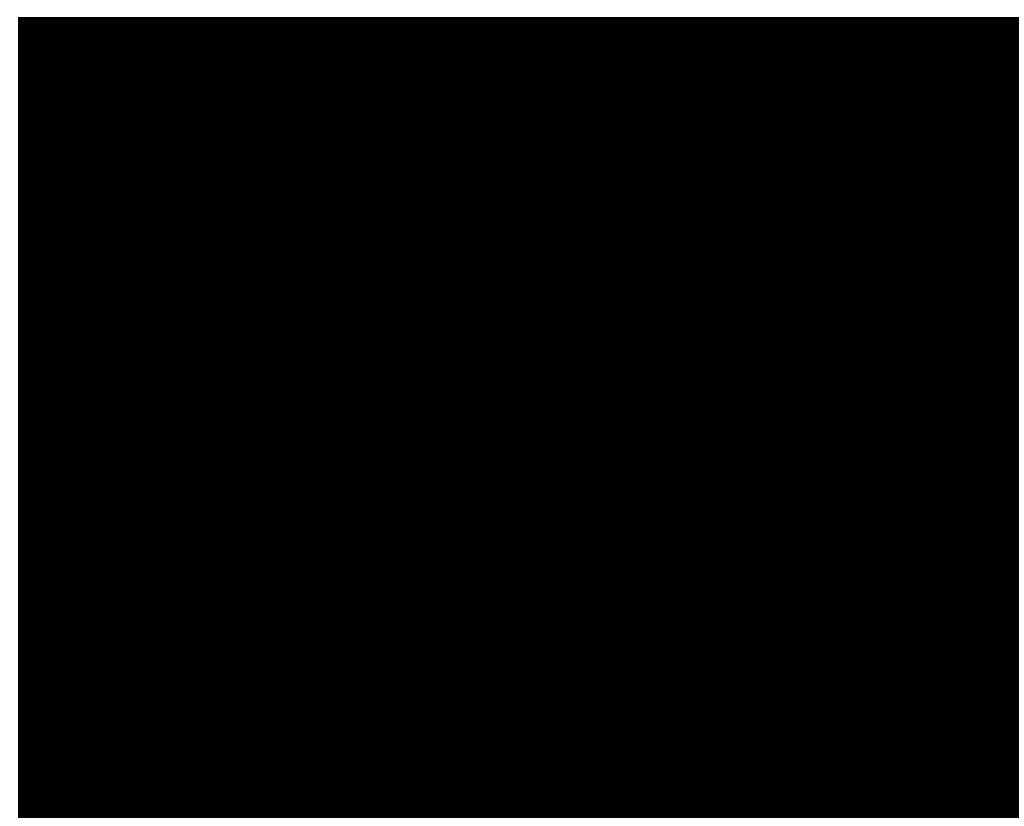

Figure 7.

Correlation of $A_{z z}$ with the dihedral angle of the axial ligand planes, $\Delta \varphi$. Denotation of the complexes is given in Table 2 . The data points for chloroplast cytochrome $b_{6}(\mathbf{1 4}, \mathbf{1 5})$ are not included in calculation of the least-squares line. 


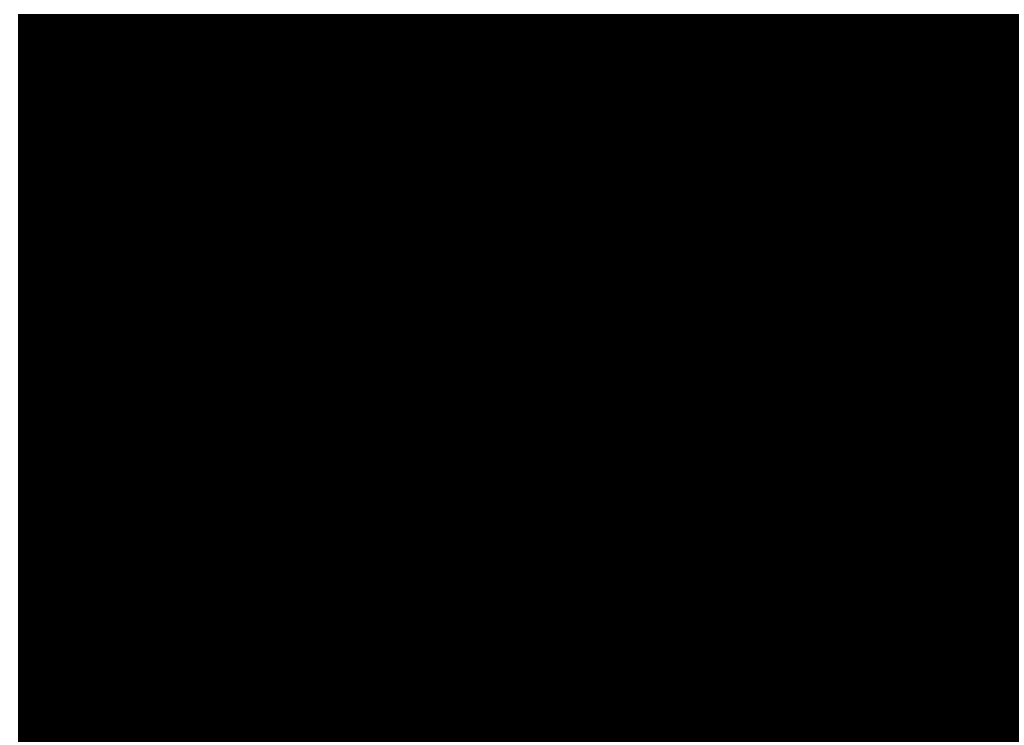

Figure 8.

Correlation of $\Delta E_{Q}$ with dihedral angle of the axial ligand planes (Denotation of the complexes is given in Table 2). Data points 3, 5, 14 and 15 are not included in the calculation of the leastsquares line. 


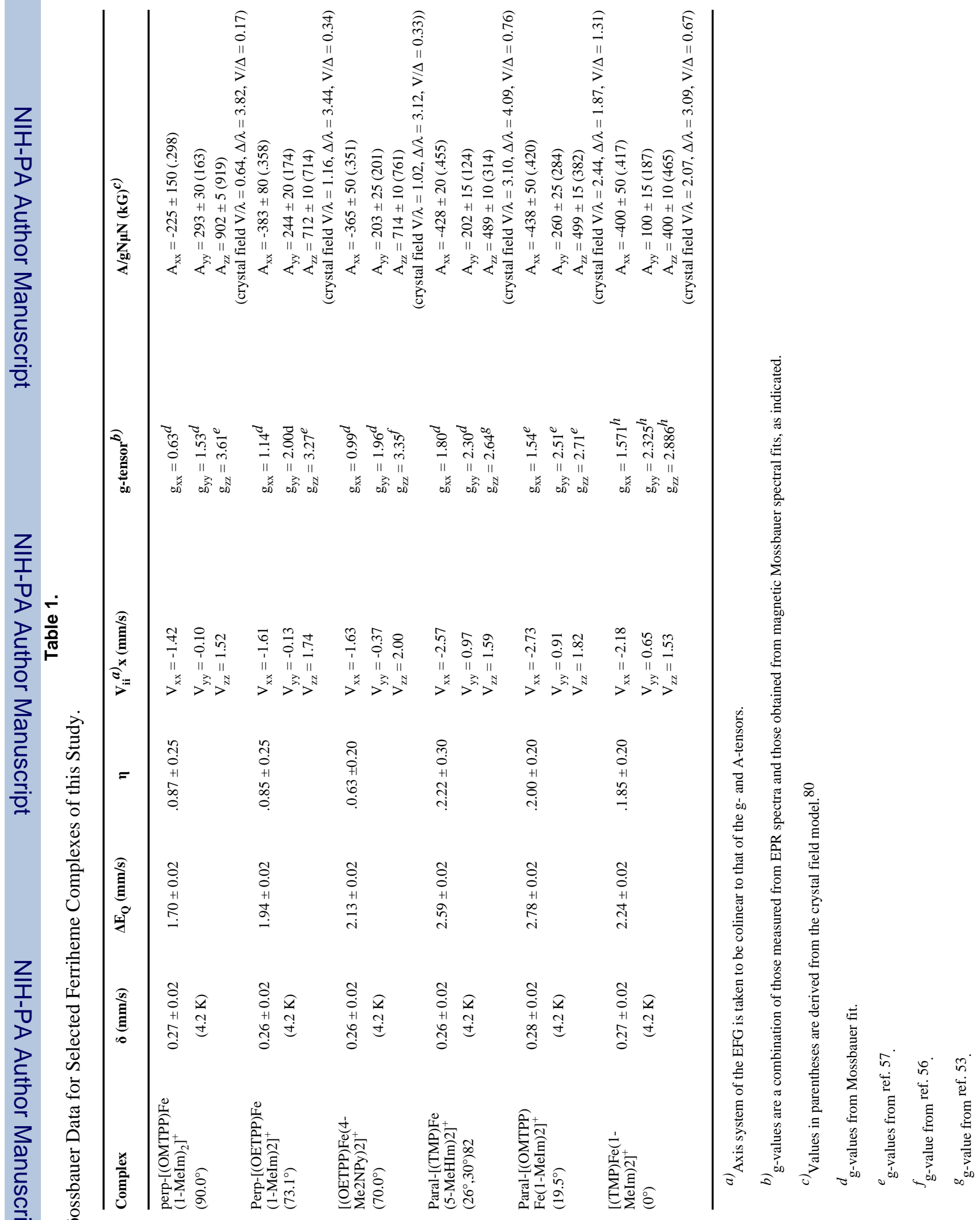




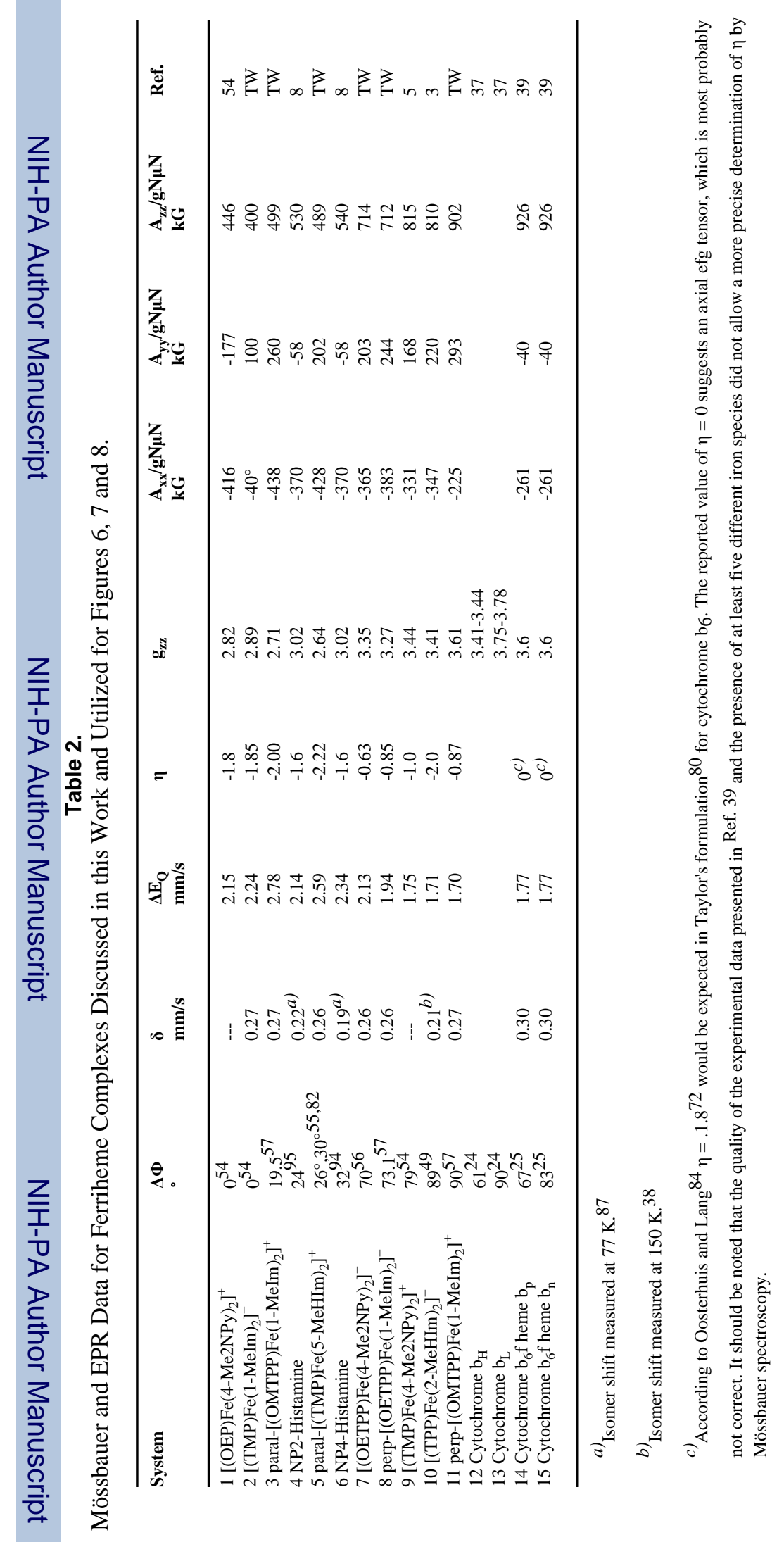

